\title{
苯并噻二唑类有机太阳能电池材料研究进展
}

\author{
和 平 $*, a, b$ 李在房 ${ }^{a}$ 侯秋飞 $a$ 王艳玲 $a$ \\ ( ${ }^{a}$ 湖北文理学院化学工程与食品科学学院 襄阳 441053) \\ ( ${ }^{b}$ 湖北文理学院低维光电材料与器件湖北省重点实验室 襄阳 441053)
}

\begin{abstract}
摘要 苯并噻二唑结构单元被广泛用来构建高光电转换效率的有机太阳能电池材料. 从聚合物太阳能电池、有机小分 子太阳能电池以及染料敏化太阳能电池三个方面系统地综述了近年来含苯并噻二唑基团的有机太阳能电池材料的研 究进展, 并对其发展趋势和应用前景做了展望.
\end{abstract}

关键词 苯并噻二唑; 有机太阳能电池; 研究进展

\section{Application of Benzothiadiazole in Organic Solar Cells}

\author{
He, Ping ${ }^{*, a, b}$ \\ Li, Zaifang ${ }^{a}$ \\ Hou, Qiufei ${ }^{a}$ \\ Wang, Yanling ${ }^{a}$ \\ ( ${ }^{a}$ College of Chemical Engineering and Food Science, Hubei University of Arts and Science, Xiangyang 441053) \\ ( ${ }^{b}$ Hubei Key Laboratory of Low Dimensional Optoelectronic Materials and Devices, Hubei University of \\ Arts and Science, Xiangyang 441053)
}

\begin{abstract}
Benzothiadiazole unit is widely used in construct organic solar cell materials. The application of benzothiadiazole in polymer solar cells, small organic molecule solar cells and dye-sensitized solar cells is reviewed, and the prospects of trends and application are also described.
\end{abstract}

Keywords benzothiadiazole; organic solar cell; research progress

随着全球对能源需求的日益增加, 煤炭、石油、天 然气等传统能源即将耗尽, 太阳能作为清洁能源因其取 之不尽、用之不竭等优点而备受人们的青睐. 太阳能电 池是将太阳能转换为电能的装置, 被认为是最有效和最 直接的太阳能利用形式. 目前, 作为无机太阳能电池代 表的多晶硅薄膜太阳能电池已经实现商业化, 但其居高 不下的成本和对环境污染严重等不利因素限制了其普 及. 近年来有机太阳能电池因其制备工艺简单、易于实 现大面积制造而且成本较低等优点, 有望在不久的将来 替代无机太阳能电池.

太阳能电池材料的吸收光谱与太阳光谱匹配程度、 载流子迁移率和合适的能级水平对于获得高的器件效 率至关重要. 苯并噻二唑基团具有一定的刚性平面结构 和良好的载流子传输特性, 同时可以与给电子基团形成 给体-受体(D-A)共轭结构, 从而获得较低的能带隙、拓 宽和增强材料的光谱吸收而被广泛用于构建高效率的
有机太阳能电池材料. 有机太阳能电池的综述已有很多 报道, 为新型高性能太阳能电池的材料设计、器件制备 提供了良好借鉴 ${ }^{[1]}$. 本文仅系统地综述近几年来苯并噻 二唑在聚合物太阳能电池、有机小分子太阳能电池和染 料敏化太阳能电池方面的研究进展.

\section{1 苯并噻二唑在聚合物太阳能电池中的应用}

太阳光的最大光子流在 $700 \mathrm{~nm}$ 左右, 为了使材料 的吸收光谱与太阳光谱达到最大程度匹配, 聚合物的最 大吸收峰也应该在 $700 \mathrm{~nm}$ 左右, 而且光谱范围也应宽 泛, 这就要求聚合物的能带隙应低于 $1.77 \mathrm{eV}$. 因此, 低 带隙的共轭聚合物近年来一直是太阳能电池材料研究 的热点 ${ }^{[2]}$. 苯并噻二唑具有较强的吸电子能力、较高的 氧化电位和较好的空气稳定性, 将其作为电子受体单元 的给体一受体共轭聚合物在本体异质结太阳能电池中获 得了较高的光电转换效率. 以下根据与苯并噻二唑结构

\footnotetext{
* E-mail: pinghe129@yahoo.com.cn

Received August 12, 2012; revised September 13, 2012; published online September 18, 2012.

Project supported by the Educational Commission of Hubei Province (No. Q20122509) and the Doctoral Starting up Foundation of Hubei University of Arts and Science.

湖北省教育厅青年基金(No. Q20122509)和湖北文理学院博士科研启动基金资助项目.
} 
单元相连接的不同类型的电子给体结构单元进行综述.

\section{1 基于苯并噻二唑与噻吩的共轭聚合物}

噻吩是较早应用在聚合物太阳能电池中的典型给 体结构单元, 以噻吩为电子给体, 苯并噻二唑作为电子 受体可以有效地构建低能隙的给体一受体型聚合物材料. 自 2001 年 Dhanabalan 小组 ${ }^{[3]}$ 首次报道基于苯并噻二唑 的聚合物太阳能电池材料以来, 苯并噻二唑类聚合物給 体材料得到了广泛关注 ${ }^{[4]}$ 。2005 年 Bundgaard 等 ${ }^{[5]}$ 报道 了苯并噻二唑与联二噻吩单元聚合时的不同聚合产物 $\mathbf{1}$ 与 2 , 虽然噻吩环上烷基链的链接方式不同，但与 $\mathrm{PC}_{61} \mathrm{BM}$ 混合制备的太阳能电池器件中却表现了相同的 能量转换效率, 均达到 $0.024 \%$. 但是以单纯的聚合物为 活化层时, 器件的能量转换效率却有很大差别. 2006 年, Wienk 等 ${ }^{[6]}$ 报道了在噻吩 3,4 位上均连接烷氧基的噻吩苯并噻二唑共轭聚合物 3 (Chart 1), 以 3 为给体材料, $\mathrm{PC}_{61} \mathrm{BM}$ 为受体(质量比为 $1: 4$ )制备的太阳能电池器件 的性能为: $V_{\mathrm{oc}}=0.77 \mathrm{~V}, J_{\mathrm{sc}}=2.8 \mathrm{~mA} / \mathrm{cm}^{2}, \mathrm{FF}=42 \%$, $\mathrm{PCE}=0.9 \%$.

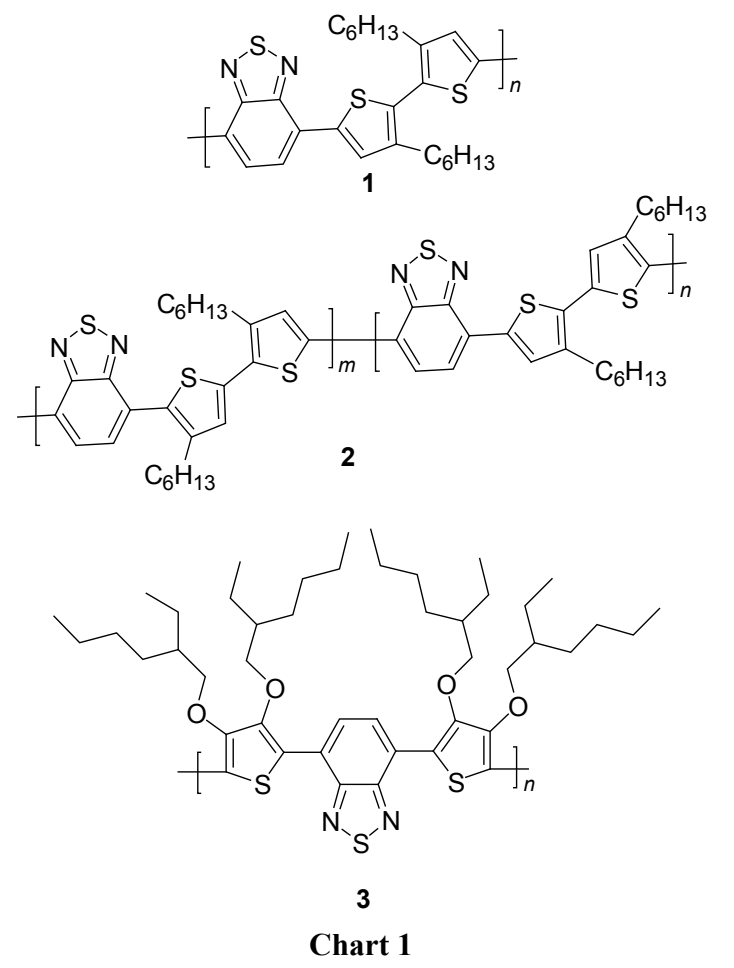

通过改变聚合物主链上噻吩单元的数目则可以较 好地调节材料的能带隙, 如 2007 年 Bundgaard 等 ${ }^{[7]}$ 报道 了聚合物 4 (Chart 2), 其能带隙为 $1.65 \mathrm{eV}$, 可以实现与 太阳光谱的较好匹配, 以其为给体材料, 以 $\mathrm{PC}_{61} \mathrm{BM}$ 为 受体(质量比为 $1: 2$ ) 制备的太阳能电池器件的性能为: $V_{\mathrm{oc}}=0.59 \mathrm{~V}, J_{\mathrm{sc}}=2.6 \mathrm{~mA} / \mathrm{cm}^{2}, \mathrm{FF}=39 \%, \mathrm{PCE}=0.62 \%{ }^{[8]}$. 进一步对器件性能优化表明, 在 1,2-二氯苯为溶剂, 每 分钟 2000 转时旋涂 $10 \mathrm{~s}, 110{ }^{\circ} \mathrm{C}$ 退火 $10 \mathrm{~min}$, 能量转换
效率可以提高到 $1.0 \%{ }^{[9]}$.

2010 年 $\mathrm{Lim}$ 等 ${ }^{[10]}$ 报道了新型聚合物材料 5 的合成, 该材料的吸收光谱在整个可见光区，能带隙为 $1.57 \mathrm{eV}$, 且空穴迁移率高达 $0.025 \mathrm{~cm}^{2} / \mathrm{Vs}$, 以其为给体材料, 以 $\mathrm{PC}_{71} \mathrm{BM}$ 为受体(质量比为 $1: 2$ ) 制备的太阳能电池器件 的性能结果为: $V_{\mathrm{oc}}=0.54 \mathrm{~V}, J_{\mathrm{sc}}=5.29 \mathrm{~mA} / \mathrm{cm}^{2}, \mathrm{FF}=$ $35 \%, \mathrm{PCE}=1.00 \%$ (Chart 3) 能量转换效率不高的原因主 要来自于 PCBM 的聚集以及由此所带来的电荷传递不 均衡.

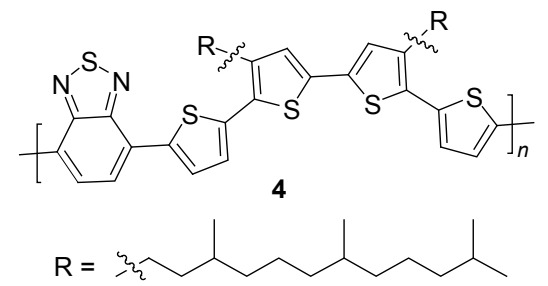

Chart 2

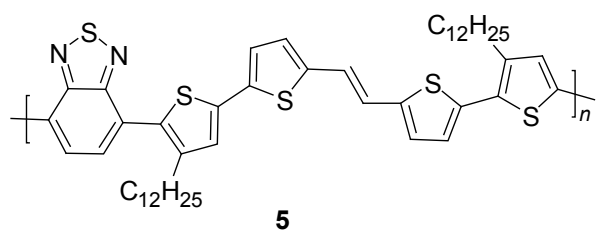

Chart 3

2011 年李永舫课题组 ${ }^{[11]}$ 报道了甲基取代的苯并噻 二唑-噻吩单元与己基取代的联二噻吩以不等物质的量 比聚合而成的产物 6 (Chart 4), 以其为給体，以 $\mathrm{PC}_{71} \mathrm{BM}$ 为受体(质量比为 $1: 3$ ) 制备的太阳能电池器件的能量转 换效率达到 $0.87 \%$ ，当加入 $1 \%$ 的 1,8 -辛二硫醇， $130{ }^{\circ} \mathrm{C}$ 退火 $15 \mathrm{~min}$ 后, 能量转换效率得到大幅度提高, 达到 $1.98 \%$. 器件性能的提高主要归结于添加剂与退火处理 成功的提高了激子在 D-A 界面的分离，同时改善了活化 层的 形貌.

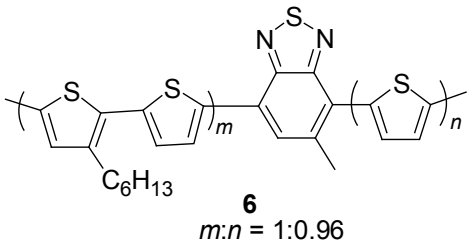

Chart 4

\section{2 基于苯并噻二唑与芴的共轭聚合物}

荡是光电材料中的明星分子，具有较大的刚性平面 结构. 芴基聚合物因具有一定的双极传输特性和优异的 光、热稳定性而在光电材料领域备受关注. Svensson 课 题组在芴参与的苯并噻二唑聚合物太阳能电池材料的 研究方面做了大量的工作，2006 年，他们 ${ }^{[12]}$ 报道了新型 
聚合物給体材料 7 (Chart 5), 对溶剂笁选发现, 以氯仿 和氯苯为混合溶剂, 以 7 为给体材料, $\mathrm{PC}_{61} \mathrm{BM}$ 为受体材 料(质量比为 $1: 3$ )制备的太阳能电池器件的最优化性能 为: $V_{\mathrm{oc}}=1.03 \mathrm{~V}, J_{\mathrm{sc}}=6.2 \mathrm{~mA} / \mathrm{cm}^{2}, \mathrm{FF}=43 \%, \mathrm{PCE}=$ $2.8 \%$.

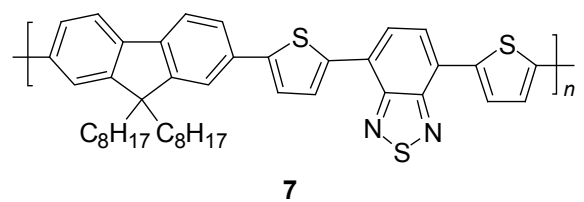

Chart 5

Sloof 等 ${ }^{[13]}$ 在聚合物 7 的基础上将 $C_{8}$ 链改成 $C_{10}$ 直 链, 合成聚合物 8 (Chart 6), 通过对活性层光的吸收研 究发现, 当厚度为 $140 \mathrm{~nm}$ 时性能最佳, 继续增加活性层 厚度, 并不能有效地提高器件的光伏转换效率, 与 $\mathrm{PC}_{61} \mathrm{BM}$ 组成的太阳能电池器件的最优化性能结果为: $V_{\mathrm{oc}}=0.99 \mathrm{~V}, J_{\mathrm{sc}}=7.7 \mathrm{~mA} / \mathrm{cm}^{2}, \mathrm{FF}=54 \%, \mathrm{PCE}=4.2 \%$. 2006 年, Pei 等 ${ }^{[14]}$ 将给电子性更强的烷氧基链代替烷基 链合成了聚合物 9 (Chart 6), 以 9 为给体材料, $\mathrm{PC}_{61} \mathrm{BM}$ 为受体 (质量比为 $1: 4$ ) 制备的太阳能电池的器件性能 为: $V_{\mathrm{oc}}=0.76 \mathrm{~V}, J_{\mathrm{sc}}=4.31 \mathrm{~mA} / \mathrm{cm}^{2}, \mathrm{FF}=49 \%, \mathrm{PCE}=$ $1.6 \%$. 而以 9 为给体材料, $\mathrm{PC}_{71} \mathrm{BM}$ 为受体材料时(质量 比为 $1: 4)$ 制备的太阳能电池器件的性能为 ${ }^{[15]}: V_{\mathrm{oc}}=$ $0.76 \mathrm{~V}, J_{\mathrm{sc}}=6.1 \mathrm{~mA} / \mathrm{cm}^{2}, \mathrm{FF}=55 \%, \mathrm{PCE}=2.4 \%$. 从上述 聚合物结构到器件的性能可以看出, 烷氧基比烷基具有 更强的给电子能力, 导致了聚噻吩衍生物的 HOMO 能 级升高, 致使光伏器件的开路电压降低, 能量转换效率 下降. 2009年, $\mathrm{CaO}$ 等 $^{[16]}$ 设计合成了聚合物 10 12 (Chart 7), 并对这类化合物的光物理性质、电化学性质以及光 伏性质进行了对照研究, 结果发现, 烷基取代位置的不 同对其性能影响较大, 聚合物 12 制备的光伏器件性能 最高 $(\mathrm{PCE}=2.63 \%)$, 未经器件优化时, 其能量转换效率 高于聚合物 $7(\mathrm{PCE}=2.02 \%)$, 通过增加噻吩单元的数 目, 提高了光电转换效率.

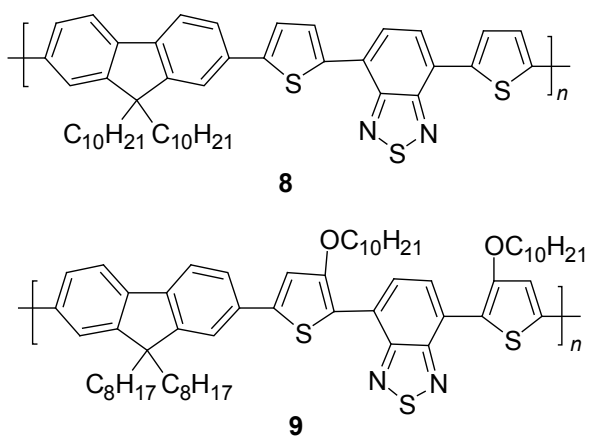

Chart 6

为了进一步研究该类聚合物的太阳能电池性能,
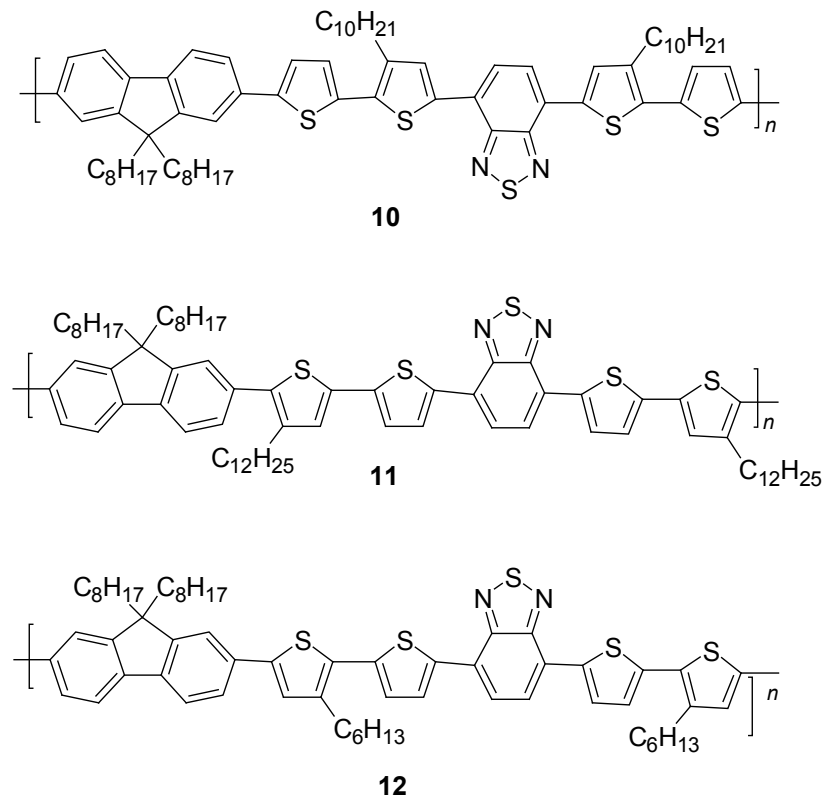

Chart 7

Boudreault 等 ${ }^{[17]}$ 将芴的 9 位用硅取代得到硅芴，再与 4,7二噻吩-苯并噻二唑聚合得到 13 (Chart 8), 以 13 为电子 给体材料, $\mathrm{PC}_{61} \mathrm{BM}$ 为受体(质量比为 $1: 2$ ) 制备的太阳能 电池器件的性能优化结果为: $V_{\mathrm{oc}}=0.90 \mathrm{~V}, J_{\mathrm{sc}}=9.5$ $\mathrm{mA} / \mathrm{cm}^{2}, \mathrm{FF}=50.7 \%, \mathrm{PCE}=5.4 \%{ }^{[18]}$. 高的能量转换效率 要归功于它相对较低的 HOMO 能级, 宽的吸收光谱 (350 750 nm) 和较高的空穴迁移率 $\left(1 \times 10^{-3} \mathrm{~cm}^{2} \cdot \mathrm{V}^{-1}\right.$. $\mathrm{s}^{-1}$, FET 法).

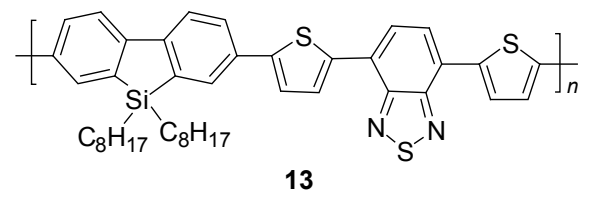

Chart 8

为了考察芴取代基以及电子给体单元对聚合物材 料光电性能的影响, 2011 年 $\mathrm{Zhu}$ 等 ${ }^{[19]}$ 在聚合物 7 的基础 上, 调节给电子单元和吸电子单元的比例, 设计合成了 一系列聚合物 14 (Chart 9)，并将咔唑基团引入到苆的 9 位取代基上，合成了新型聚合物材料 15 (Chart 9), 制备 的光伏器件性能研究表明, 咔唑的引入极大的提高了短 路电流和能量转换效率. 例如, 分别以 14 和 15 为给体 材料, 以 $\mathrm{PC}_{61} \mathrm{BM}$ 为受体材料(质量比为 $1: 3$ )制备的太 阳能电池器件的最优化性能结果分别为: 聚合物 $14 \mathrm{c}$ 时: $V_{\mathrm{oc}}=0.79 \mathrm{~V}, J_{\mathrm{sc}}=4.84 \mathrm{~mA} / \mathrm{cm}^{2}, \mathrm{FF}=40 \%, \mathrm{PCE}=1.54 \%$, 聚合物 15c 时: $V_{\mathrm{oc}}=0.74 \mathrm{~V}, J_{\mathrm{sc}}=9.68 \mathrm{~mA} / \mathrm{cm}^{2}, \mathrm{FF}=34 \%$, $\mathrm{PCE}=2.41 \%$.

2011年, Asawapirom 等 ${ }^{[20]}$ 又报道了聚合物 16 (Chart 10), 并研究了其光伏性能. 结果表明, 随着聚合物体系 


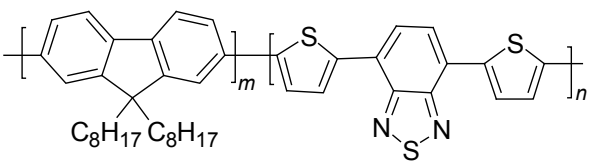

14a $m: n=19: 1$

14b $m: n=17: 3$

14c $m: n=7: 3$

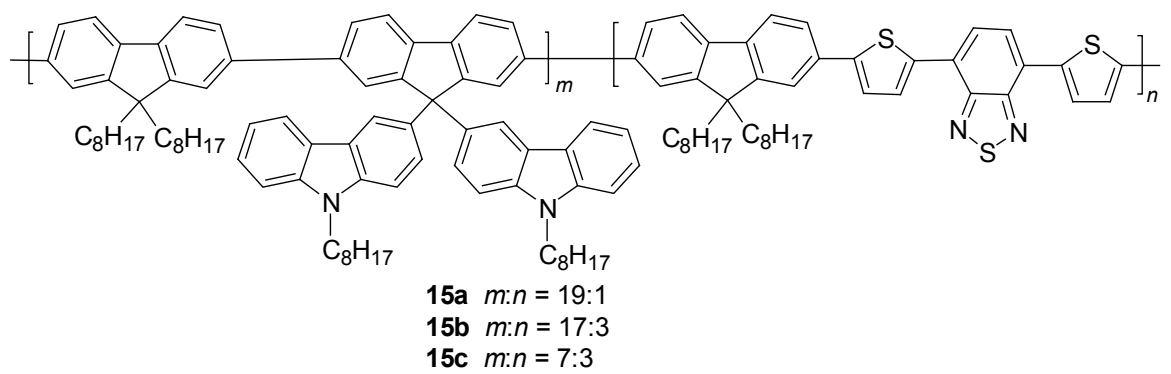

Chart 9

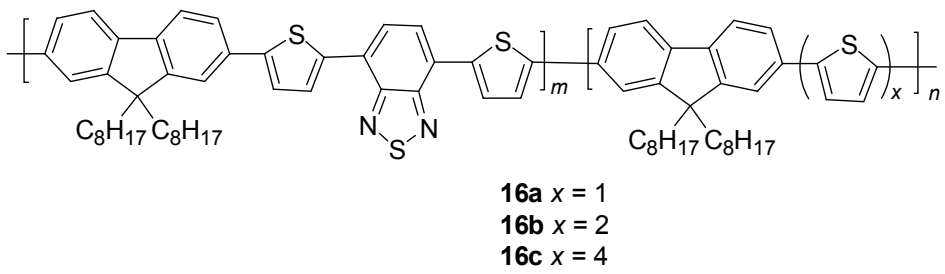

Chart 10

中噻吩单元数目的增加, 器件短路电流增大, 光电转换 效率随之增大, 其中, 以聚合物 $\mathbf{1 6 c}$ 为给体材料, 以 PCBM 为受体材料(质量比为 $1: 1$ ) 时, 太阳能电池器件 的能量转换效率最高, 具体结果为: $V_{\mathrm{oc}}=0.75 \mathrm{~V}, J_{\mathrm{sc}}=$ $4.55 \mathrm{~mA} / \mathrm{cm}^{2}, \mathrm{FF}=37 \%, \mathrm{PCE}=1.25 \%$. 与聚合物 7 相比, 由于噻吩-荡基团的引入, 该系列聚合物的平面规整性 以及共轭效应进一步加强, 能量转换效率得到提高.

\section{3 基于苯并噻二唑和咔唑的共轭聚合物}

咔唑环系与荡较类似, 咔唑环上的氮原子因具有给 电子能力, 使得咔唑具有较好的给电子能力, 此外, 咔 唑环的氮原子上可以连接烷基链, 以调节推电子能力和 聚合物溶解性. 但是由于咔唑的均聚物能带隙较宽 (3.0 $\mathrm{eV}$ ), 必须与吸电子单体进行聚合形成 D-A 聚合物, 才 能够得到窄带隙聚合物材料. 其中苯并噻二唑与咔唑形 成的共聚物材料得到了广泛研究.

2007 年 Leclerc 等 ${ }^{[21]}$ 报道了由苯并噻二唑作为强吸 电子单元与咔唑形成共聚物 17 (Chart 11), 聚合物的能 带隙降至 $1.88 \mathrm{eV}$, 以 17 为给体材料, $\mathrm{PC}_{61} \mathrm{BM}$ 为受体 (质 量比为 $1: 4$ )制备的太阳能电池器件的性能为: $V_{\mathrm{oc}}=$ $0.89 \mathrm{~V}, J_{\mathrm{sc}}=6.92 \mathrm{~mA} / \mathrm{cm}^{2}, \mathrm{FF}=63 \%, \mathrm{PCE}=3.6 \%$. 而同 等条件下采用喹喔啉、吡啶并噻二唑、噻吩并吡嗪、苯 并噁二唑等作为电子受体单元聚合得到的给体材料, 能 量转换效率均小于 $2.5 \%{ }^{[22]}$. Heeger 等 ${ }^{[23]}$ 在进一步器件
优化的基础上, 以 $\mathrm{PC}_{71} \mathrm{BM}$ 为受体(质量比为 $1: 4$ )制备 的太阳能电池器件的性能结果为: $V_{\mathrm{oc}}=0.88 \mathrm{~V}, J_{\mathrm{sc}}=10.6$ $\mathrm{mA} / \mathrm{cm}^{2}, \mathrm{FF}=66 \%, \mathrm{PCE}=6.1 \%$, 内量子效率接近 $100 \%$, 得到了截至目前为止报道的能量转换效率最高的咔唑 基聚合物太阳能电池器件. 进一步的研究表明, 材料 $\mathbf{1 7}$ 在 $350{ }^{\circ} \mathrm{C}$ 氮气氛围及 $150{ }^{\circ} \mathrm{C}$ 的空气中都非常稳定 ${ }^{[24]}$, 而且最近研究发现其器件的寿命可以长达 7 年之久, 成 为目前为止报道的寿命最长的聚合物太阳能电池 ${ }^{[25]}$. Qin 等 ${ }^{[26]}$ 则在聚合物 17 的基础上, 将苯并噻二唑的苯环 上进行烷氧基取代，改变咔唑上氮原子的取代基，得到 了新型基于咔唑为供电子单元, 苯并噻二唑为电子受体 单元的聚合物 18 (Chart 11), 聚合物 18 在常规溶剂中表 现出良好的溶解性, 以 $\mathbf{1 8}$ 为给体材料, $\mathrm{PC}_{71} \mathrm{BM}$ 为受体
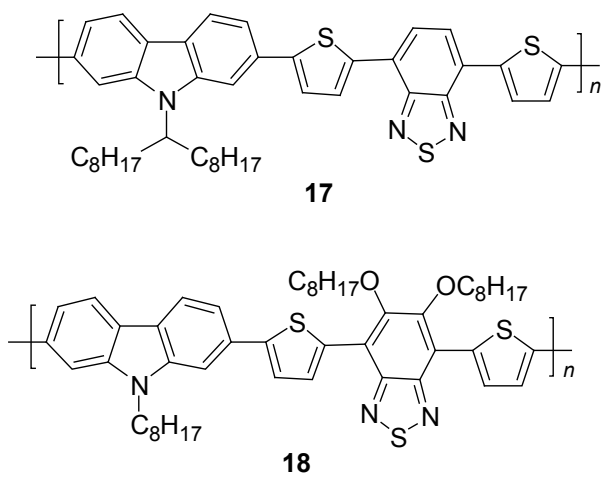

Chart 11 
(质量比为 $1: 2.5$ )制备的太阳能电池器件的性能结果 为: $V_{\mathrm{oc}}=0.81 \mathrm{~V}, J_{\mathrm{sc}}=9.6 \mathrm{~mA} / \mathrm{cm}^{2}, \mathrm{FF}=69 \%, \mathrm{PCE}=$ 5.4\%. 而将化合物 18 上咔唑氮原子取代基进一步改变 成芳基将导致能量转换效率的降低, 说明了咔唑环上烷 基供电子链在调节聚合物能带隙时的重要作用 ${ }^{[27]}$.

2011 年, Yang 等 ${ }^{[28]}$ 首次报道了两个苯并噻二唑直 接相连作为电子受体单元制备的系列聚合物太阳能电 池材料, 其中以聚合物材料 19 为給体时, 太阳能电池的 能量转换效率最高. 具体的太阳能电池器件的性能结果 为: $V_{\mathrm{oc}}=0.66 \mathrm{~V}, J_{\mathrm{sc}}=7.16 \mathrm{~mA} / \mathrm{cm}^{2}, \mathrm{FF}=44 \%, \mathrm{PCE}=$ $2.07 \%$ (Chart 12). 这一研究, 为含有连苯并噻二唑类聚 合物太阳能电池材料的发展提供了经验借鉴.

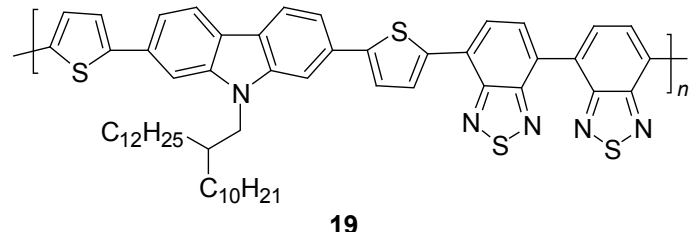

Chart 12

吲哚并 $[3,2-b]$ 咔唑可以看成是两个稠环咔唑, 给电 子能力比单个的咔唑更强, 5 个共平面的稠杂环提供了 大的共轭体系，稳定性和空穴迁移率进一步提高，因而
也常作为电子给体单元应用于 D-A 型共轭聚合物给体 材料的合成中 ${ }^{[29]}$, 如 2009 年 Zhou 等 ${ }^{[30]}$ 以吲哚并 $[3,2-b]$ 咔唑电子给体单元, 以苯并噻二唑-噻吩为电子受体单 元，通过调节噻吩单元的数目，分别合成了 20 和 21 两 种聚合物材料(Chart 13), 分别以 20 和 21 为给体材料, 以 $\mathrm{PC}_{61} \mathrm{BM}$ 为受体材料(质量比为 $1: 3$ )制备的太阳能电 池器件的性能分别为: 以 20 为给体材料时, $V_{\mathrm{oc}}=0.94 \mathrm{~V}$, $J_{\mathrm{sc}}=3.77 \mathrm{~mA} / \mathrm{cm}^{2}, \mathrm{FF}=41 \%, \mathrm{PCE}=1.47 \%$; 以 21 为给体 材料时: $V_{\mathrm{oc}}=0.90 \mathrm{~V}, J_{\mathrm{sc}}=4.83 \mathrm{~mA} / \mathrm{cm}^{2}, \mathrm{FF}=48 \%$, $\mathrm{PCE}=2.07 \%$.

$\mathrm{Xia}$ 等 $^{[31]}$ 巧妙地以苯并噻二唑-噻吩并 $[3,2-b]$ 噻吩作 为供电子单元，合成了新型聚合物 22 (Chart 14), 以 22 为给体材料, $\mathrm{PC}_{71} \mathrm{BM}$ 为受体(质量比 1:2)制备的太阳 能电池器件的性能为: $V_{\mathrm{oc}}=0.75 \mathrm{~V}, J_{\mathrm{sc}}=6.02 \mathrm{~mA} / \mathrm{cm}^{2}$, $\mathrm{FF}=42 \%, \mathrm{PCE}=2.4 \% . \mathrm{Lu}$ 等 $^{[32]}$ 则在苯并噻二唑-噻吩单 元上通过向噻吩环上引入取代基，较好的平衡了溶解性 与结晶度之间的关系，得到了聚合物 23 (Chart 14), 以 23 为给体材料, $\mathrm{PC}_{61} \mathrm{BM}$ 为受体(质量比 1：2)制备的太 阳能电池器件的性能结果为: $V_{\mathrm{oc}}=0.69 \mathrm{~V}, J_{\mathrm{sc}}=9.17$ $\mathrm{mA} / \mathrm{cm}^{2}, \mathrm{FF}=57 \%, \mathrm{PCE}=3.6 \%$.

稠杂环因环的共平面而显示出更强的共轭效应, Cheng 等 ${ }^{[33]}$ 将环戊二烯并噻吩和咔唑稠合在一起得到

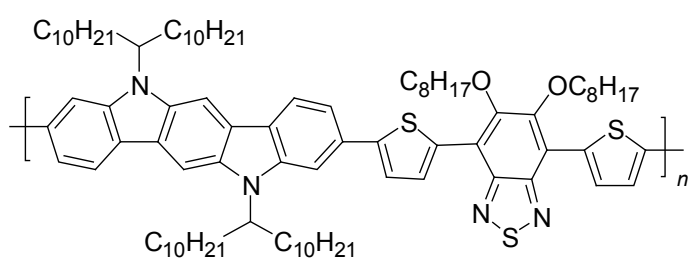

20

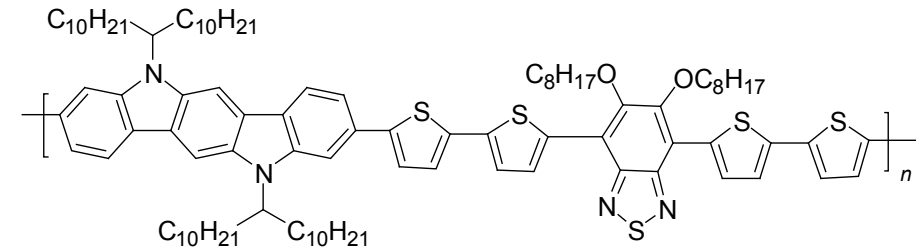

21

\section{Chart 13}

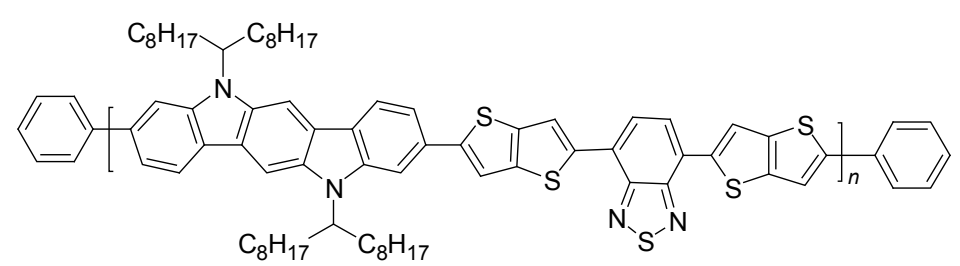

22

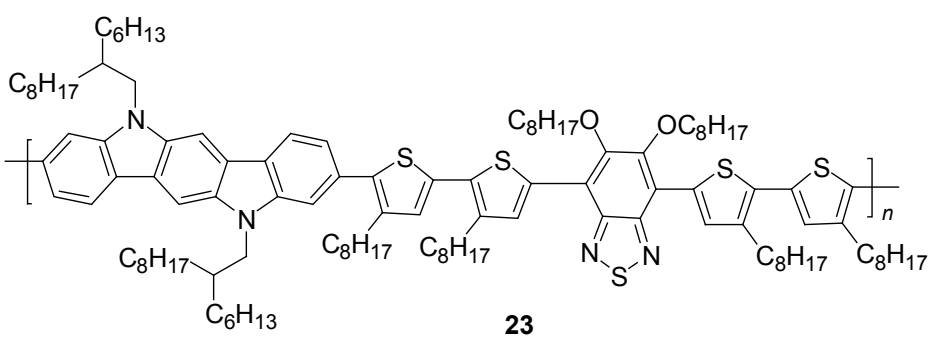

\section{Chart 14}


了 “梯形” 的稠杂环电子给体单元: 双噻吩并环戊二烯 并咔唑, 为考察电子受体单元对材料性能的影响, 作者 将苯并噻二唑、并二吡咯酮、哒嗪等与分别与上述单体 通过 Stille 聚合得到了一系列新型给受体型聚合物给体 材料 24 (Chart 15), 以聚合物 24 为给体材料, $\mathrm{PC}_{71} \mathrm{BM}$ 为 受体材料制备了太阳能电池器件, 性能测试结果表明, 以苯并噻二唑为电子受体材料时聚合物 24a 能量转换效 率最高, 具体结果为: $V_{\mathrm{oc}}=0.74 \mathrm{~V}, J_{\mathrm{sc}}=10.3 \mathrm{~mA} / \mathrm{cm}^{2}$, $\mathrm{FF}=60 \%, \mathrm{PCE}=4.6 \%$.
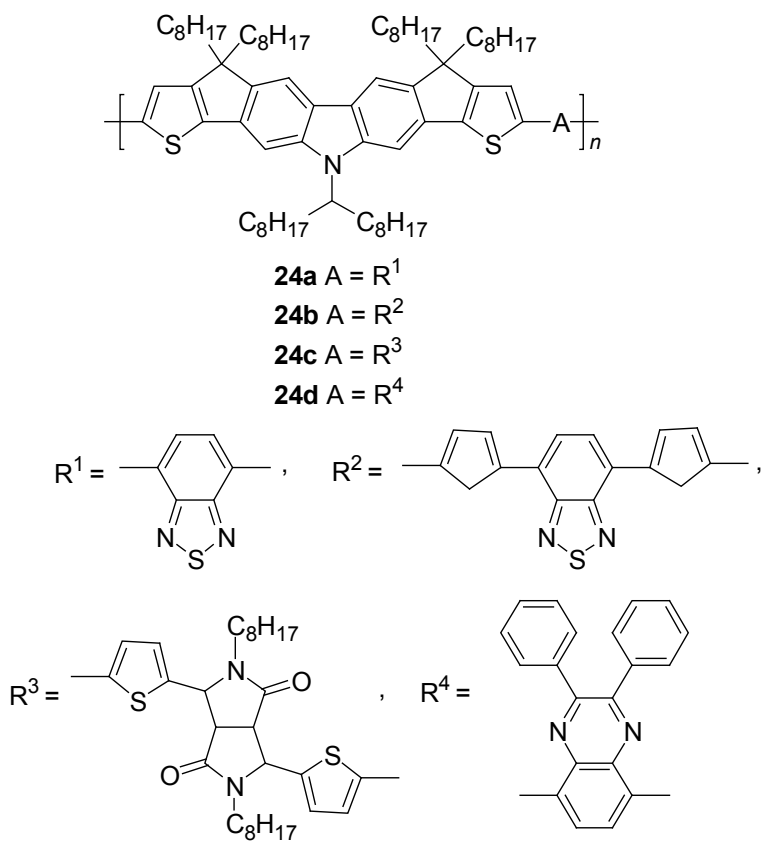

Chart 15

\section{4 基于苯并噻二唑和环戊二烯并双噻吩的共轭聚合} 物

环戊二烯并双噻吩衍生物与芴的结构相似, 也具有 很好的共平面结构, 2006年 Mühlbacher 等 ${ }^{[34]}$ 首次报道了 基于环戊二烯并双噻吩和苯并噻二唑为单体的聚合物 给体材料 25 (Chart 16), 聚合物 25 具有较窄的能带隙 $(1.4 \mathrm{eV})$, 初步光伏性能测试结果表明, 以 25 为给体材 料, $\mathrm{PC}_{71} \mathrm{BM}$ 为受体材料制备的太阳能电池器件的能量 转换效率达到 $3.2 \%$, 光电导性研究 ${ }^{[35]}$ 和进一步的器件 优化得到的器件性能结果为 ${ }^{[36]}: V_{\mathrm{oc}}=0.65 \mathrm{~V}, J_{\mathrm{sc}}=11.8$ $\mathrm{mA} / \mathrm{cm}^{2}, \mathrm{PCE}=3.5 \%$. 器件的优异性能主要归功于聚合 物具有很强的光吸收性能和高的空穴迁移率 $(1 \times$ $\left.10^{-3} \mathrm{~cm}^{2} \cdot \mathrm{V}^{-1} \cdot \mathrm{s}^{-1}\right)$. 另外, 他们通过调节受体单元结构以 及与给体单元的比例, 设计合成了无规则聚合物 26 (Chart 16), 该类聚合物的光吸收范围可以进行调节, 随 着苯并噻二唑受体单元的增加而移向长波范围, 为新型 给体材料的设计提供了很好的借鉴. Meerholz 等 ${ }^{[37]}$ 在 25
的基础上, 将苯并噻二唑两边引入噻吩合成了聚合物 27 (Chart 16), 以 27 为给体材料, $\mathrm{PC}_{61} \mathrm{BM}$ 为受体材料, 氯苯为溶剂, 加入 $5 \%$ 的苯甲醛, 制备太阳能电池器件 最优化性能为: $V_{\mathrm{oc}}=0.60 \mathrm{~V}, \mathrm{FF}=42 \%, \mathrm{PCE}=2.1 \%$.

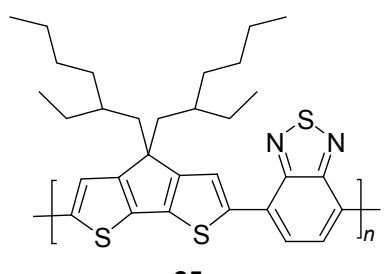

25

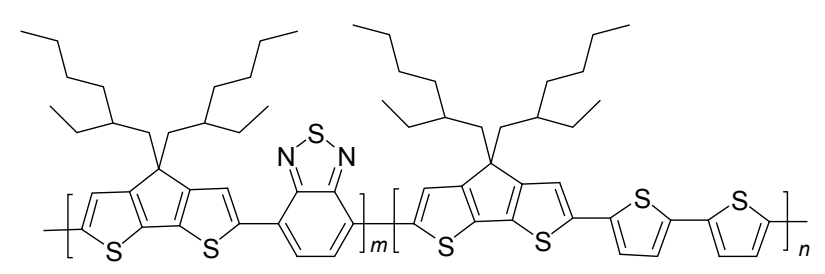

26a $m: n=2: 1$

26b $m: n=1: 1$

26c $m: n=1: 2$

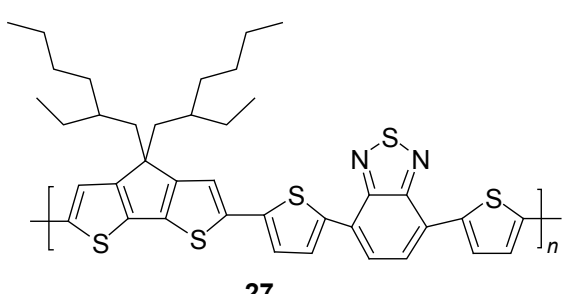

27

\section{Chart 16}

Heeger 等 ${ }^{[39]}$ 在器件制备时, 采用二硫代辛二醇作 为溶剂添加剂进行了太阳能电池器件的性能优化, 以 25 为给体材料, $\mathrm{PC}_{71} \mathrm{BM}$ 为受体材料制备的太阳能电池 器件的最终优化性能为: $V_{\mathrm{oc}}=0.62 \mathrm{~V}, J_{\mathrm{sc}}=16.2 \mathrm{~mA} / \mathrm{cm}^{2}$, $\mathrm{FF}=55 \%, \mathrm{PCE}=5.5 \%{ }^{[38]}$. 进一步的研究表明，不仅二 硫代辛二醇, 二碘代辛二烷也可以作为溶剂添加剂改善 活性层的形貌，进而提高能量转换效率. 基于 $\mathbf{2 5}$ 对光谱 的吸收范围, Heeger 等 ${ }^{[40]}$ 设计在溶液中将 25 与齐聚噻 吩 P3HT 一起制备了叠层太阳能电池器件, 仍然以 $\mathrm{PC}_{71} \mathrm{BM}$ 为受体材料制备太阳能电池器件, 串联电池最 优化性能果为: $V_{\mathrm{oc}}=1.24 \mathrm{~V}, J_{\mathrm{sc}}=7.8 \mathrm{~mA} / \mathrm{cm}^{2}, \mathrm{FF}=67 \%$, $\mathrm{PCE}=6.5 \%$.

2011 年 Lee 等 ${ }^{[41]}$ 报道了在上述研究基础上, 改变环 戊二烯并双噻吩上取代基的结构，设计合成的新型聚合 物材料 28 (Chart 17), 光谱吸收范围从 $300 \mathrm{~nm}$ 一直延续 到 $850 \mathrm{~nm}$, 以 28 为给体材料, $\mathrm{PC}_{61} \mathrm{BM}$ 为受体材料制备 的太阳能电池器件的性能结果为: $V_{\mathrm{oc}}=0.62 \mathrm{~V}, J_{\mathrm{sc}}=5.37$ $\mathrm{mA} / \mathrm{cm}^{2}, \mathrm{FF}=41 \%, \mathrm{PCE}=1.37 \%$, 同等条件下, 与 $\mathrm{P} 3 \mathrm{HT}$ 制备的太阳能电池器件相比, 性能参数在 $300 \mathrm{~h}$ 后仍然 较为稳定. 


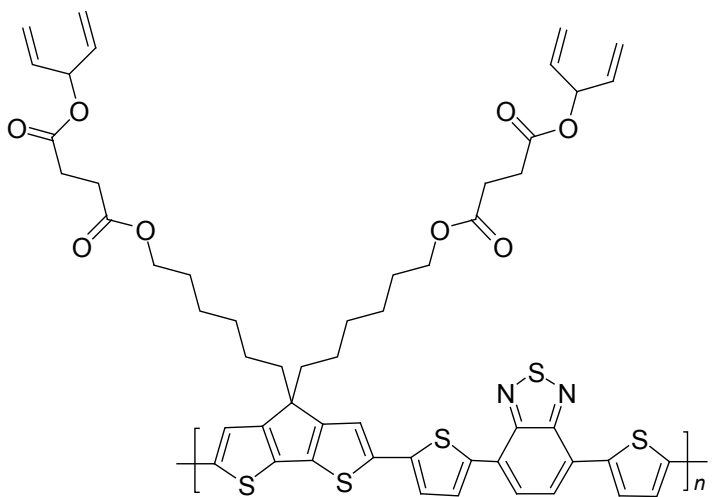

28

\section{Chart 17}

2012 年, Lee 等 ${ }^{[42]}$ 在聚合物 27 的基础上, 设计了一 系列聚合物材料 29 (Chart 18), 对聚合物中噻吩单元上 烷基取代基对材料性能的影响进行了讨论, 研究发现, 当噻吩单元上无取代时, 能量转换效率最高, 达到 $3.8 \%$, 并且发现, 烷基链的取代位置对活化层形貌有重 要影响.

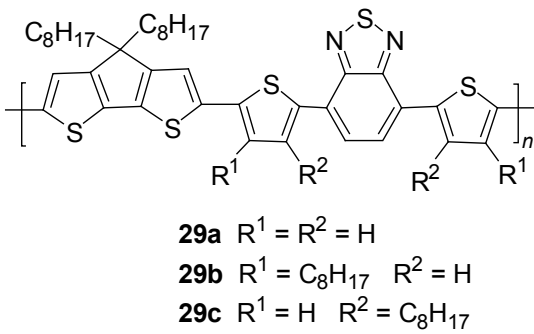

\section{Chart 18}

将环戊二烯并双噻吩的 4 位碳用其他原子取代, 合 成新型聚合物材料也有很多尝试. 如 2008 年, Hashimoto 等 $^{[43]}$ 报道了 4 位为氮原子取代的吡咯并双噻吩衍 生物与 4,7-二噻吩-苯并噻二唑形成的窄带隙聚合物 30 (Chart 19), 该聚合物具有良好的溶解性, 以其为给体材 料, $\mathrm{PC}_{61} \mathrm{BM}$ 为受体材料制备的太阳能电池器件的初步 测试性能结果为: $V_{\mathrm{oc}}=0.52 \mathrm{~V}, J_{\mathrm{sc}}=9.47 \mathrm{~mA} / \mathrm{cm}^{2}, \mathrm{FF}=$ $44 \%, \mathrm{PCE}=2.18 \% .2009$ 年 Yue 等 ${ }^{[44]}$ 报道了吡咯并双噻 吩衍生物与苯并噻二唑聚合得到的一系列衍生物 31 (Chart 19), 对氮原子上烷基链长度的不同进行了考察, 以 $\mathrm{PC}_{61} \mathrm{BM}$ 为受体材料制备的太阳能电池器件性能测试 结果表明, 当取代基为二戊基时(31c), 能量转换效率最 高, 具体器件性能结果为: $V_{\mathrm{oc}}=0.54 \mathrm{~V}, J_{\mathrm{sc}}=11.9$ $\mathrm{mA} / \mathrm{cm}^{2}, \mathrm{FF}=44 \%, \mathrm{PCE}=2.8 \%$, 该研究为高性能材料 设计提高了更为细致的研究思路.

Yang 等 ${ }^{[45]}$ 在聚合物 25 的基础上将 4 位碳用硅取代 合成电子给体单元, 仍然以苯并噻二唑为电子受体单

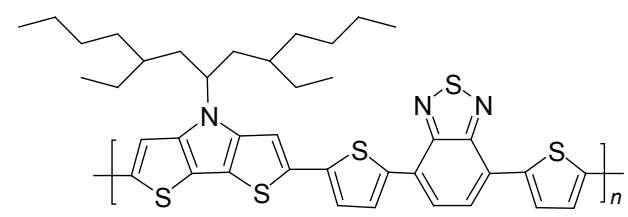

30

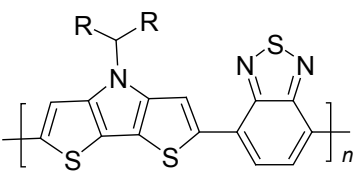

31a $R=\mathrm{C}_{8} \mathrm{H}_{17}$
31b $\mathrm{R}=\mathrm{C}_{6} \mathrm{H}_{13}$
31c $\mathrm{R}=\mathrm{C}_{5} \mathrm{H}_{11}$

Chart 19

元，合成了新的共轭聚合物 32 (Chart 20), 以 32 为电子 给体材料, 以 $\mathrm{PC}_{71} \mathrm{BM}$ 为受体材料(质量比为 $1: 1$ )制备 的的太阳能电池器件的性能结果为: $V_{\mathrm{oc}}=0.68 \mathrm{~V}, J_{\mathrm{sc}}=$ $12.7 \mathrm{~mA} / \mathrm{cm}^{2}, \mathrm{FF}=55 \%, \mathrm{PCE}=5.1 \% .2009$ 年, Bazan 等 ${ }^{[46]}$ 采用微波方法合成了化合物 33 和 34 (Chart 20), 分 别以其为给体材料，以 $\mathrm{PC}_{71} \mathrm{BM}$ 为受体材料制备了太阳 能电池器件，结果表明，4位硅取代得到的化合物 34 制 备的器件性能明显较高, 具体性能结果为: $V_{\mathrm{oc}}=0.57 \mathrm{~V}$, $J_{\mathrm{sc}}=17.3 \mathrm{~mA} / \mathrm{cm}^{2}, \mathrm{FF}=61 \%, \mathrm{PCE}=5.9 \%, 2012$ 年 Reynolds 等 ${ }^{[47]}$ 在结构 32 的基础上进一步修饰, 将二噻 吩并硅杂环戊二烯两边引入噻吩单元, 并且改变分子中 苯并噻二唑与二噻吩并硅杂环戊二烯的比例，设计合成 了一系列新型聚合物分子并对其光伏性能进行了研究, 进一步证实了该类分子的具有很高的电子迁移率.

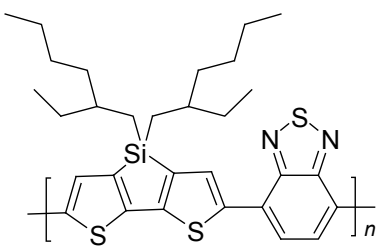

32

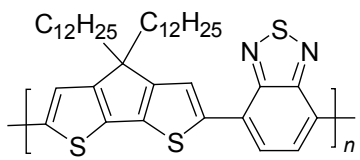

33

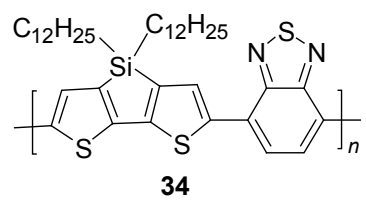

Chart 20

环成二烯并双噻吩类供电子单元作为良好的电子 
给体得到了广泛的研究, Heeney 等 ${ }^{[48]}$ 在聚合物 34 的基 础上将 4 位硅原子用锗取代合成的电子给体单元更是取 得了很好的研究成果, 短路电流 $J_{\mathrm{sc}}$ 高达 $18.6 \mathrm{~mA} / \mathrm{cm}^{2}$, 并且该类聚合物结构稳定, 便于制备, 分子量容易控制.

\section{5 基于苯并噻二唑和苯并[1,2- $\left.b: 4,5-b^{\prime}\right]$ 二噻吩的共 轭聚合物}

苯并 $[1,2-b: 4,5-b]$ 二噻吩作为电子给体单元在合成 给体一受体共轭聚合物材料上也得到了广泛关注 ${ }^{[49]}$, 特 别是苯并噻二唑作为电子受体单元合成的该类材料取 得了较好的光电转换效率. 例如, 2009 年 Yang 等 ${ }^{[50]}$ 报 道了聚合物 35 和 36 (Chart 21), 分别以两者为给体材料, 以 $\mathrm{PC}_{61} \mathrm{BM}$ 为受体材料, 对制备的太阳能电池的性能进 行了研究. 经性能优化, 以 33 为给体材料, 以 $\mathrm{PC}_{61} \mathrm{BM}$ 为电子受体材料制备的的太阳能电池器件的性能较好, 具体结果为: $V_{\mathrm{oc}}=0.84 \mathrm{~V}, J_{\mathrm{sc}}=6.28 \mathrm{~mA} / \mathrm{cm}^{2}, \mathrm{FF}=36.9 \%$, $\mathrm{PCE}=1.95 \%$.

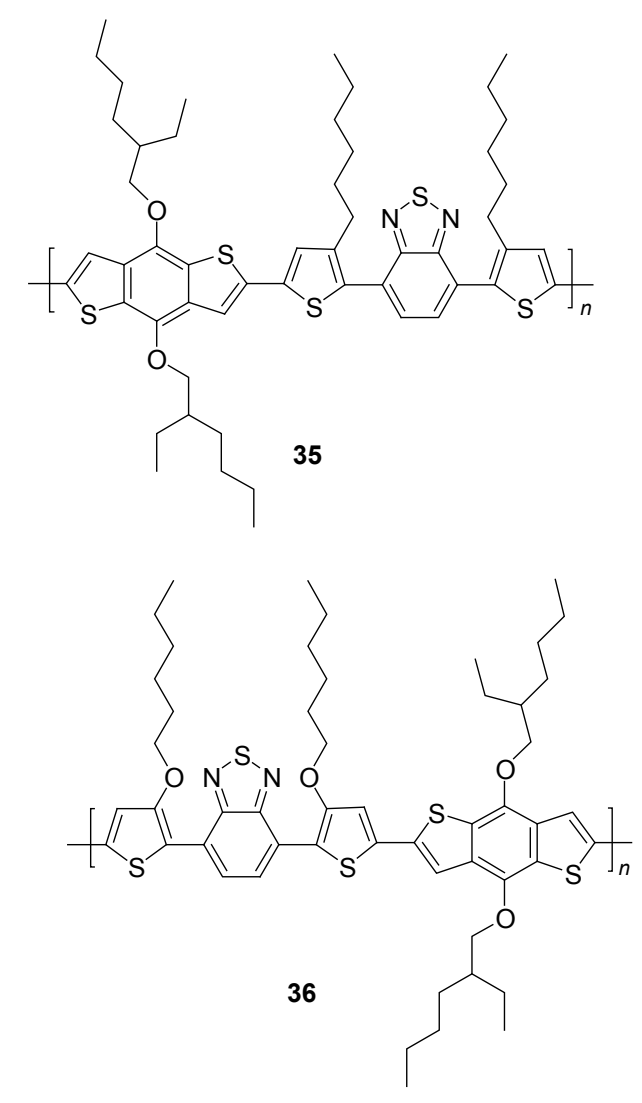

Chart 21

随后 Hou 等 ${ }^{[51]}$ 在苯并 $[1,2-b: 4,5-b$ ]二噻吩单元的基 础上, 设计了二维的共轭结构: 4,8-二噻吩-苯并[1,2- $b$ : 4,5- $b$ ]二噻吩, 以此为电子给体单元, 以二噻吩-苯并噻 二唑为受体单元, 合成了共轭聚合物 37 (Chart 22), 以 37 为给体材料, 以 $\mathrm{PC}_{71} \mathrm{BM}$ 为电子受体材料制备的的太
阳能电池器件的初步性能测试结果为: $V_{\mathrm{oc}}=0.92 \mathrm{~V}$, $J_{\mathrm{sc}}=10.7 \mathrm{~mA} / \mathrm{cm}^{2}, \mathrm{FF}=57.5 \%, \mathrm{PCE}=5.66 \%$.

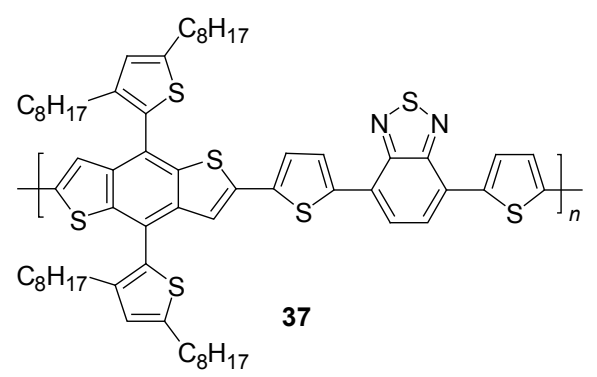

Chart 22

最近 Peng 等 ${ }^{[52]}$ 将化合物 37 的结构进行了进一步修 饰，将苯并噻二唑的苯环上引入烷氧基取代基以及氟原 子, 合成了聚合物 38 和 39 (Chart 23), 取代基的引入进 一步改善了太阳能电池器件的性能, 以 38 和 39 为给体 材料, 以 $\mathrm{PC}_{71} \mathrm{BM}$ 为受体材料 $(1: 2)$ 制备的太阳能电池 器件的性能优化结果分别为: 38 为给体材料时: $V_{\mathrm{oc}}=$ $0.82 \mathrm{~V}, J_{\mathrm{sc}}=12.53 \mathrm{~mA} / \mathrm{cm}^{2}, \mathrm{FF}=54.9 \%, \mathrm{PCE}=5.64 \%$. 以 39 为给体材料时: $V_{\mathrm{oc}}=0.86 \mathrm{~V}, J_{\mathrm{sc}}=12.05 \mathrm{~mA} / \mathrm{cm}^{2}$, $\mathrm{FF}=59.9 \%, \mathrm{PCE}=6.21 \%$, 氟原子作为吸电子基团引入 笨并噻二唑体系, 降低了分子的 HOMO 能级, 相应的使 开路电压 $V_{\mathrm{oc}}$ 得以提到, 另一方面, 由于氟原子可以和 氢原子、氟原子形成分子内/分子间的氢键, 在一定程度 上影响了器件的活化层形貌 ${ }^{[53]}$.
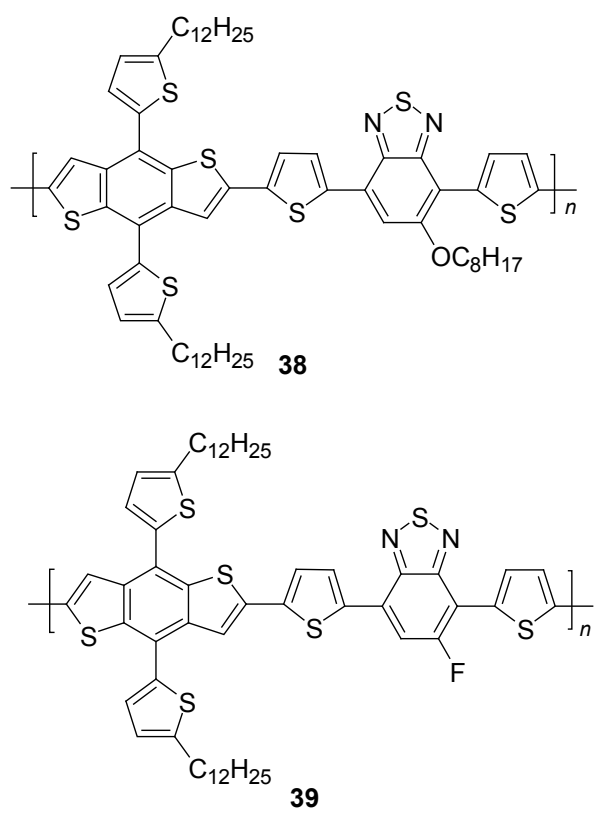

Chart 23

Wang 等 ${ }^{[54]}$ 最近报道了菜并双噻二唑为吸电子单元 的给受体型给体聚合物材料 40 (Chart 24), 与苯并噻二 唑为吸电子单元的聚合物 41 (Chart 24)相比, 光吸收明 显红移, 具有更高的空穴迁移率, 器件性能明显优越. 
分别以聚合物 40 和 41 为给体材料, 以 $\mathrm{PC}_{71} \mathrm{BM}$ 为受体 材料(质量比为 $1: 1$ ) 制备的太阳能电池器件的性能差别 较大. 以 40 为给体材料时: $V_{\mathrm{oc}}=0.80 \mathrm{~V}, J_{\mathrm{sc}}=11.71$ $\mathrm{mA} / \mathrm{cm}^{2}, \mathrm{FF}=61 \%, \mathrm{PCE}=6.00 \%$; 以 41 为给体材料时: $V_{\mathrm{oc}}=1.00 \mathrm{~V}, J_{\mathrm{sc}}=5.80 \mathrm{~mA} / \mathrm{cm}^{2}, \mathrm{FF}=34.6 \%, \mathrm{PCE}=$ $2.11 \%$.
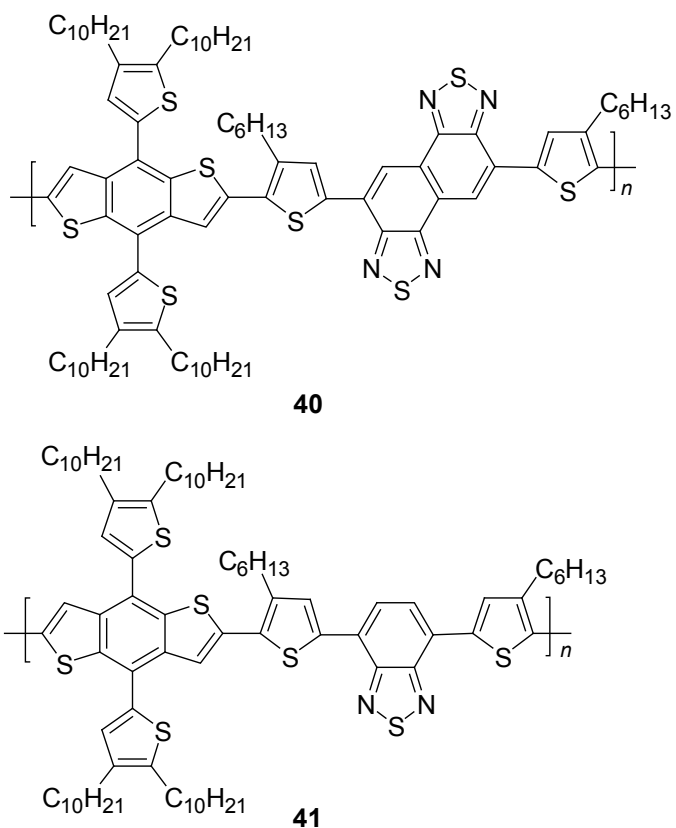

Chart 24
1.6 基于苯并噻二唑和二噻吩并苯并二狮的共轭聚合 物

二噻吩并苯并二狮因具有较好的共平面性而应用 于聚合物太阳能电池给体材料中, 如聚合物二噻吩并苯 并二狮 42 (Chart 25), 能帯隙为 $2.08 \mathrm{eV}$, 以 $\mathrm{PC}_{71} \mathrm{BM}$ 为 受体材料, 能量转换效率为 $3.3 \%{ }^{[55]}$, 苯并噻二唑单元作 为电子受体可以调节聚合物的能级, 当苯并噻二唑与二 噻吩并苯并二狮共聚时, 得到的聚合物 43, 44 (Chart 25) 的能带隙进一步减低, 分别达到 1.70 和 $1.76 \mathrm{eV}$, 太阳能 电池器件转换效率得到提高, 其中聚合物 43 因能帯隙 更好的与太阳能光谱匹配, 器件性能最高, 具体结果为: 43 为给体材料时: $V_{\mathrm{oc}}=0.80 \mathrm{~V}, J_{\mathrm{sc}}=10.1 \mathrm{~mA} / \mathrm{cm}^{2}, \mathrm{FF}=$ $53 \%, \mathrm{PCE}=4.3 \%$, 以 44 为给体材料时: $V_{\mathrm{oc}}=0.84 \mathrm{~V}$, $J_{\mathrm{sc}}=8.7 \mathrm{~mA} / \mathrm{cm}^{2}, \mathrm{FF}=53 \%, \mathrm{PCE}=3.9 \%{ }^{[56]}$.

Zhang 等 ${ }^{[57]}$ 将上述给电子单元上的芳环进行改变, 采用溶解性更好的烷基取代基合成了聚合物 45 (Chart 26), 分别以噻吩-二噻唑、噻吩-四溙、噻吩-苯并噻二 唑等为电子受体单元，对不同电子受体单元对材料性能 的影响进行了考察, 不同的电子受体单元很好的调节了 聚合物的能帯隙, 以苯并噻二唑为电子受体单元的聚合 物 45c, 能带隙最小, 达到 $1.68 \mathrm{eV}$, 吸收峰与太阳光谱 匹配最好, 能量转换效率进一步得到提高. 以 $\mathbf{4 5 d}$ 为给 体材料, 以 $\mathrm{PC}_{71} \mathrm{BM}$ 为受体材料(质量比为 $1: 3$ ) 制备的 太阳能电池器件的性能优化结果为: $V_{\mathrm{oc}}=0.82 \mathrm{~V}, J_{\mathrm{sc}}=$ $13.27 \mathrm{~mA} / \mathrm{cm}^{2}, \mathrm{FF}=56.7 \%, \mathrm{PCE}=6.17 \%$.
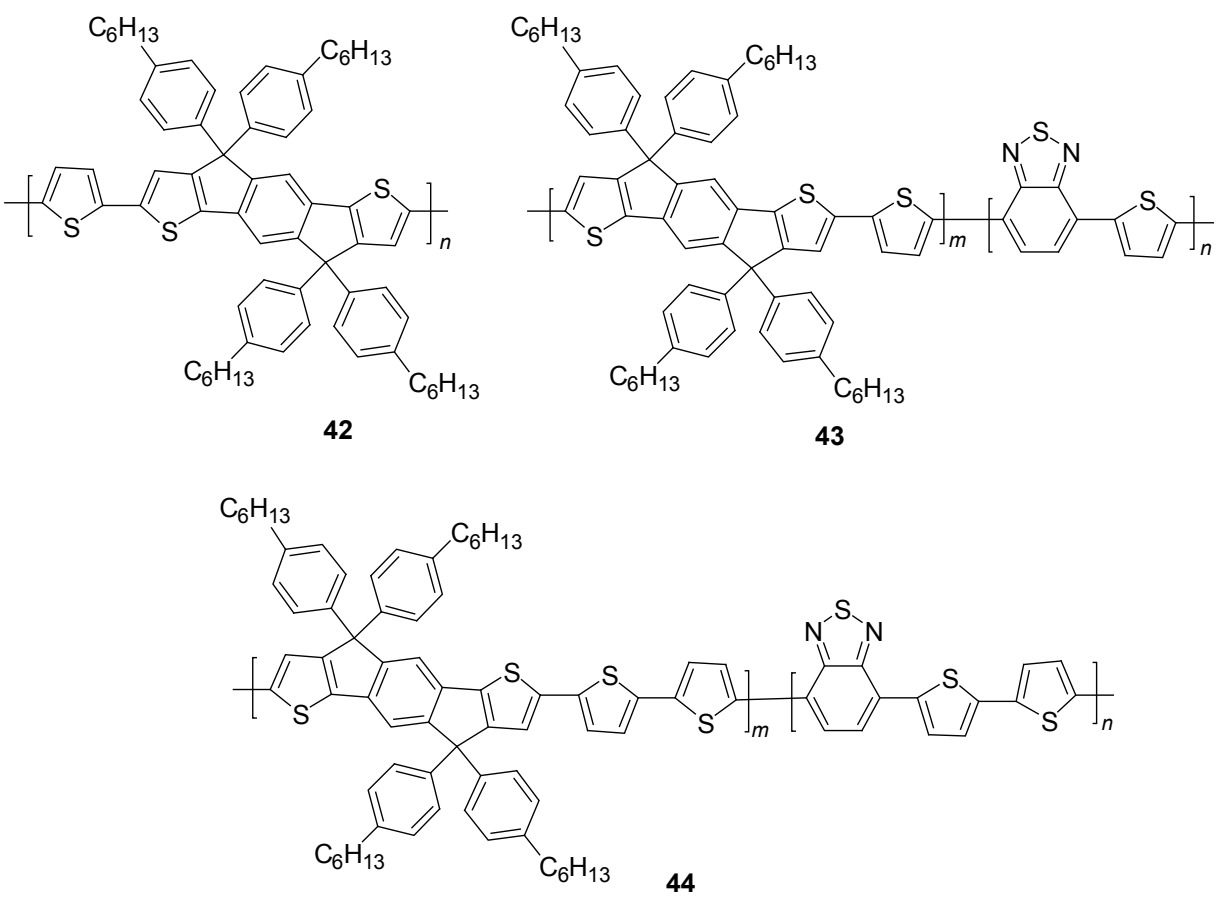

Chart 25 


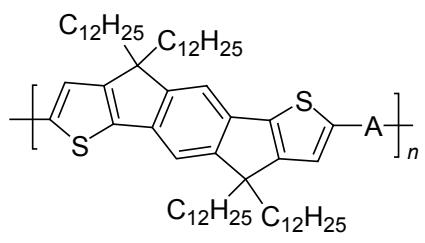

45a $A=R^{1}, 45 b \quad A=R^{2}, 45 c A=R^{3}, 45 d \quad A=R^{4}$

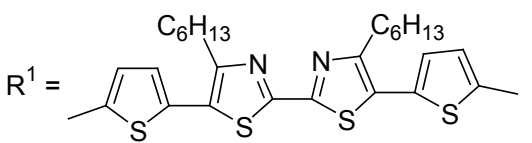<smiles>[R]=[Fe]c1ccc(-c2nc3sc(-c4ccc(C)s4)nc3s2)s1</smiles><smiles></smiles>

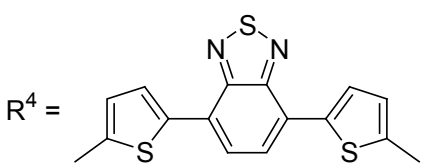

Chart 26

\section{7 基于苯并噻二唑和炔烃的共轭聚合物}

炔烃聚合物发现较早, 能带隙较宽, 苯并噻二唑与 炔烃的的聚合物, 再与金属铂键合作为太阳能电池给体

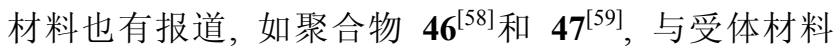
$\mathrm{PC}_{71} \mathrm{BM}$ 制备的太阳能电池器件的能量转换效率均达到 4\%以上, 苯并噻二唑基团的引入很好的调节了该类含 金属聚合物材料能带隙, 为有机金属聚合物在太阳能电 池方面的应用提供了很好的发展方向(Chart 27).
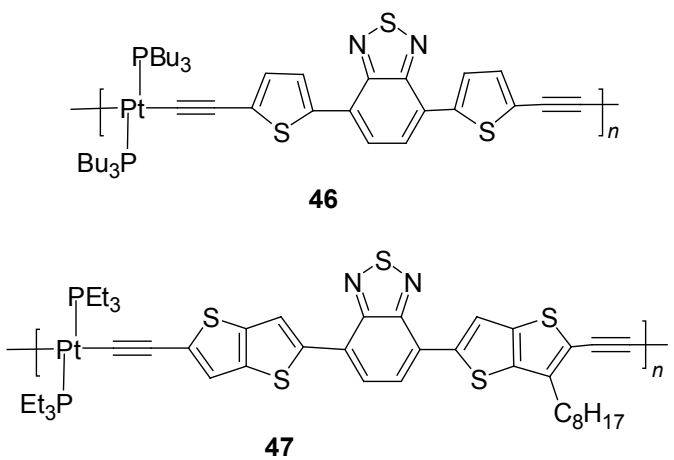

Chart 27

以上简单地对苯并噻二唑在 $\mathrm{D}-\mathrm{A}$ 型聚合物给体材 料中的应用进行了归纳, 由此我们不难看出, 以苯并噻 二唑衍生物为电子受体单元的聚合物材料是目前获得 高性能聚合物太阳能电池的常用材料之一, 随着各种窄 带隙聚合物的合理设计, 聚合物太阳能电池的能量转换 效率将不断得到提高.

\section{2 苯并噻二唑在有机小分子太阳能电池中的应 用}

有机小分子因其重复性好、分子量固定、易于提纯 等优点在太阳能电池领域受到越来越多的关注，而基于 苯并噻二唑的小分子太阳能电池是其中最为重要的一 部分, 下面就苯并噻二唑衍生物作为太阳能电池的给体 材料或受体材料进行简要综述.

\section{1 基于苯并噻二唑的小分子给体材料在太阳能电池 中的应用}

2006 年李永舫等 ${ }^{[60]}$ 首次报道了苯并噻二唑在小分 子中作为电子受体单元制备成给体材料 48 (Chart 28), 小分子 48 以苯并噻二唑为中心核，噻吩乙烯基为桥联 基团, 三苯胺为端基, 其能隙为 $1.8 \mathrm{eV}$, 表现了较宽的 吸收峰, 两个主峰在 405 和 $560 \mathrm{~nm}$, 吸收边界一直到达 $690 \mathrm{~nm}$, 作者对 48 参与的太阳能电池器件的结构进行 了优化, 结果显示, 在本体异质结器件中, 器件性能较 高, 又采用 $\mathrm{Mg}, \mathrm{Ca}, \mathrm{LiF} / \mathrm{Al}, \mathrm{Ba}$ 作为不同的阴极材料进 行了研究探讨, 以 48 为给体材料, $\mathrm{PC}_{61} \mathrm{BM}$ 为受体材料 (质量比为 $1: 1$ ) 制备的太阳能电池器件的性能结果为: $V_{\mathrm{oc}}=0.76 \mathrm{~V}, J_{\mathrm{sc}}=0.87 \mathrm{~mA} / \mathrm{cm}^{2}, \mathrm{FF}=33 \%, \mathrm{PCE}=0.26 \%$.

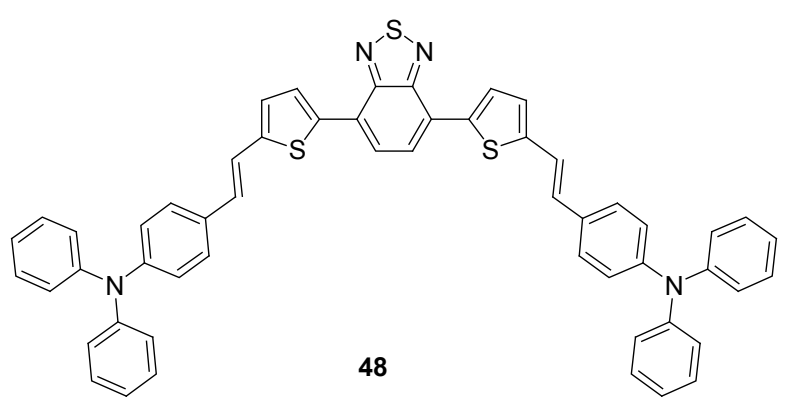

Chart 28

随后, 他们 ${ }^{[61]}$ 在三苯胺-苯并噻二唑单元构建的有 机小分子太阳能电池材料方面进行了大量的探索, 2008 年他们以苯并噻二唑为中心核, 乙烯基为桥联基团，三 苯胺为端基构建了线型给受体小分子 49 (Chart 29), 又 以三苯胺为中心核, 苯并噻二唑二乙烯基为桥联基团, 三苯胺为端基构建了星型给受体小分子 50 (Chart 29), 以 $\mathrm{PC}_{61} \mathrm{BM}$ 为受体 (质量比为 $1: 3$ ) 制备了太阳能电池器 件，当以线性小分子 49 为给体材料时的性能结果为: $V_{\mathrm{oc}}=0.84 \mathrm{~V}, J_{\mathrm{sc}}=1.25 \mathrm{~mA} / \mathrm{cm}^{2}, \mathrm{FF}=34 \%, \mathrm{PCE}=0.35 \%$; 当以星型小分子 $\mathbf{5 0}$ 为给体材料时, 太阳能电池器件的 性能结果为: $V_{\mathrm{oc}}=0.81 \mathrm{~V}, J_{\mathrm{sc}}=4.18 \mathrm{~mA} / \mathrm{cm}^{2}, \mathrm{FF}=39 \%$, $\mathrm{PCE}=1.33 \%$. 星状分子为给体材料时, 效果较好的原 因主要是星型分子具有更加宽而强的吸收峰，高的空穴 迁移率以及合适的能级. 
<smiles>C(=C/c1ccc(/C=C/c2ccc(N(c3ccccc3)c3ccccc3)cc2)c2nsnc12)\c1ccc(N(c2ccccc2)c2ccccc2)cc1</smiles>

49

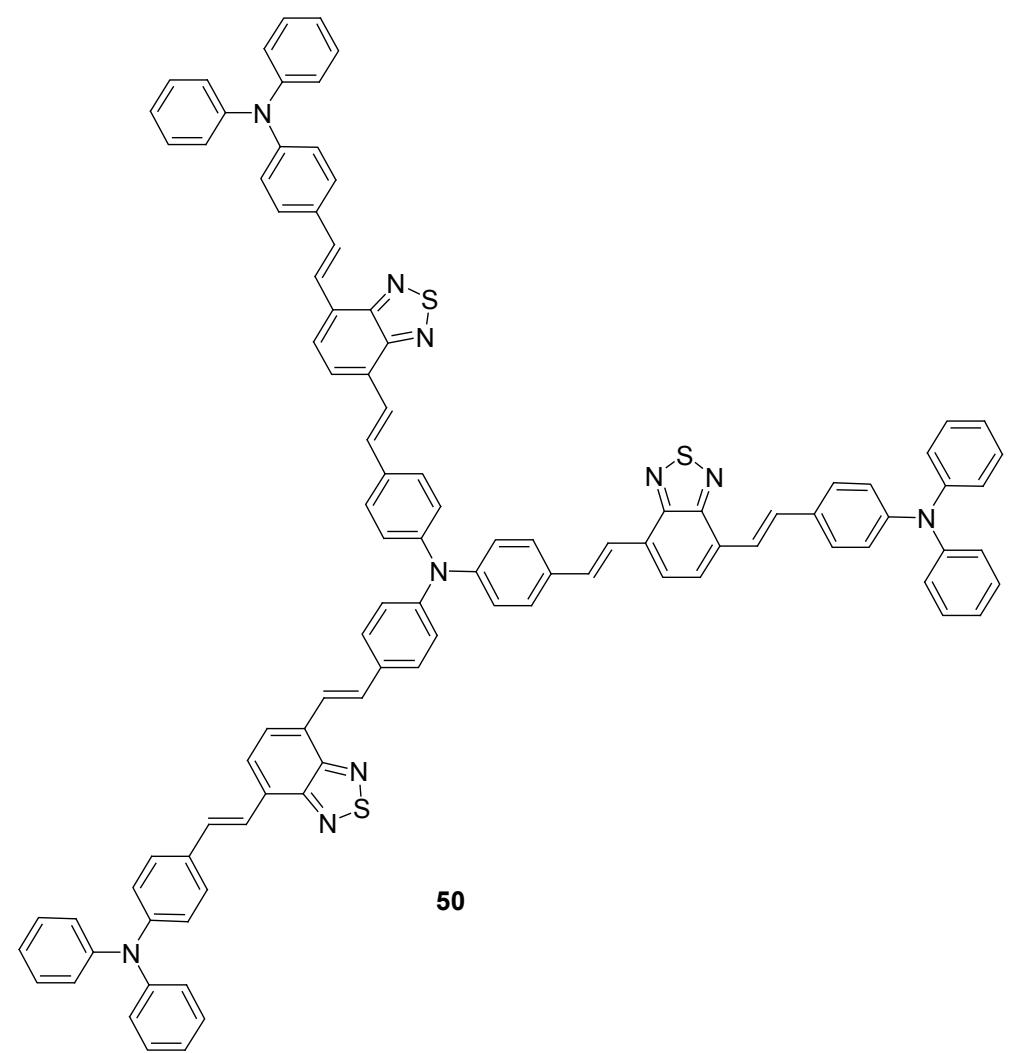

\section{Chart 29}

基于以上研究, 2009 年李永舫等 ${ }^{[62]}$ 又设计了三苯胺 为核, 苯并噻二唑为端基的小分子给受体材料 51 (Chart 30), 与化合物 $\mathbf{5 0}$ 相比, 端基三苯胺的缺失, 使得化合 物 51 的能带隙变大, 吸收光谱变窄, 与 $\mathrm{PC}_{61} \mathrm{BM}(1: 3)$ 制备的太阳能电池器件分别采用 $\mathrm{Ca} / \mathrm{Al}, \mathrm{Ba} / \mathrm{Al}$ 为阴极材 料进行了探讨, 最终的器件优化结果为 $V_{\mathrm{oc}}=0.90 \mathrm{~V}$, $J_{\mathrm{sc}}=1.54 \mathrm{~mA} / \mathrm{cm}^{2}, \mathrm{FF}=43 \%, \mathrm{PCE}=0.61 \%$.<smiles></smiles>

Chart 30

同年, Zhang 等 ${ }^{[3]]}$ 为了进一步考察分子结构对器件 性能的影响, 设计了以三苯胺为端基, 噻吩为桥联基团, 苯并噻二唑为中心核的线性小分子 $\mathbf{5 2}$ 和星型小分子 $\mathbf{5 3}$ (Chart 31), 调节桥联基团噻吩的数目, 得到了 8 个小分 子化合物, 分别以其作为给体材料, 以 $\mathrm{PC}_{71} \mathrm{BM}$ 为受体 材料, 制备的太阳能电池性能结果表明: 桥联基团为烷
基取代的单噻吩, 分子为星型结构时, 能量转换效率最 高, 即化合物 $\mathbf{5 3} \mathrm{c}$, 具体的太阳能电池器件性能结果为: $V_{\mathrm{oc}}=0.92 \mathrm{~V}, J_{\mathrm{sc}}=4.9 \mathrm{~mA} / \mathrm{cm}^{2}, \mathrm{FF}=41 \%, \mathrm{PCE}=1.8 \%$, 而同等条件下线性化合物能量转换效率稍差一些.<smiles>[R]c1ccc([R])c2nsnc12</smiles>

52a $R=R^{1}$

52b $R=R^{2}$

52c $R=R^{3}$

52d $R=R^{4}$

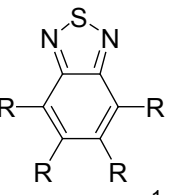

53a $R=R^{1}$

53b $\mathrm{R}=\mathrm{R}^{2}$

53c $R=R^{3}$

53d $R=R^{4}$<smiles>[R][R]=CN(c1ccccc1)c1ccc(-c2ccc(-c3ccc(C)s3)s2)cc1</smiles>

$R^{3}=$<smiles>Cc1cc(C)c(-c2ccc(N(c3ccccc3)c3ccccc3)cc2)s1</smiles>

$\mathrm{R}^{4}=$<smiles>CCCCCCc1cc(C)sc1-c1cc(C)c(-c2ccc(N(c3ccccc3)c3ccccc3)cc2)s1</smiles>

Chart 31 
为了改善星型化合物 $\mathbf{5 0}$ 的形貌进而提高能量转换 效率, 李永舫等 ${ }^{[65]}$ 在化合物 $\mathbf{5 0}$ 的基础上, 将端基三苯 胺用烷基噻吩基团取代合成了星型化合物 54 (Chart 32), 由于烷基噻吩基团极大地增加了化合物的溶解性，与受 体材料混合制备活性层时形貌得到了极大改善, 太阳能 电池器件的性能有了明显提高, 具体优化结果为: $V_{\mathrm{oc}}=$ $0.65 \mathrm{~V}, J_{\mathrm{sc}}=8.58 \mathrm{~mA} / \mathrm{cm}^{2}, \mathrm{FF}=32.7 \%, \mathrm{PCE}=2.39 \%{ }^{[64]}$. 最近他们将烷基化的齐聚噻吩为给电子基团, 仍然以吸 电子基团苯并噻二唑为桥联基团, 三苯胺为中间核, 制 备了给受体小分子化合物 55 (Chart 32), 在以 $\mathrm{PC}_{71} \mathrm{BM}$ 为受体材料制备的太阳能电池器件中, 得到目前为止可 溶解加工有机小分子太阳能电池的最高转换效率, 具体 器件性能结果为: $V_{\mathrm{oc}}=0.87 \mathrm{~V}, J_{\mathrm{sc}}=9.51 \mathrm{~mA} / \mathrm{cm}^{2}, \mathrm{FF}=$

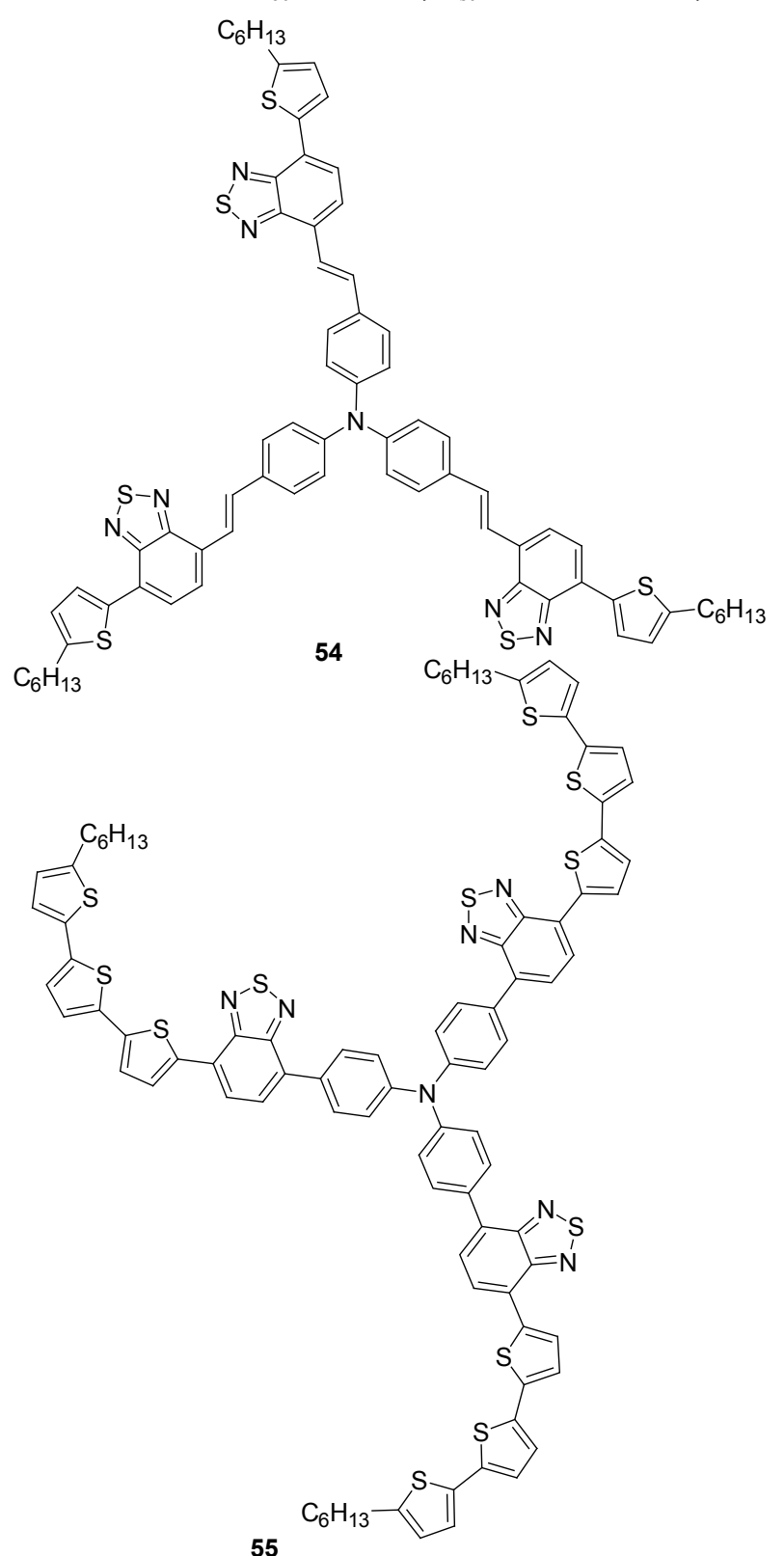

Chart 32
$52 \%, \mathrm{PCE}=4.3 \%$.

\section{2 基于苯并噻二唑的小分子受体材料在太阳能电池 中的应用}

有机太阳能电池常用的受体材料为富勒烯衍生物, 然而由于该类化合物合成复杂，价格较高，近年来关于 小分子受体材料的研究逐渐受到人们的重视, 含有苯并 噻二唑的咪唑二氧基化合物是近年来研究较热的一类 小分子受体材料. 2007 年 Sellinger 等 ${ }^{[66]}$ 首次报道了该类 小分子受体材料 56 和 57 (Chart 33), 其中，化合物 56 因 具有较低的 LUMO 能级而成为合适的太阳能电池受体 材料, 56 的 LUMO 能级和 HOMO 能级分别为: -3.49 和 $-5.87 \mathrm{eV}$, 在常见的极性溶剂中易溶, 吸收峰在 $300 \sim 500 \mathrm{~nm}$, 作者选择 A-PPE-PPV 和 P3HT 作为给体 材料制备了太阳能电池器件, 其中, 以苯一炔烃聚合物 A-PPE-PPV 为给体时, 优化结果为 $V_{\mathrm{oc}}=0.98 \mathrm{~V}, J_{\mathrm{sc}}=$ $1.20 \mathrm{~mA} / \mathrm{cm}^{2}, \mathrm{FF}=35 \%, \mathrm{PCE}=0.42 \%$. 以聚噻吩 $\mathrm{P} 3 \mathrm{HT}$ 为给体时, 优化结果为 $V_{\mathrm{oc}}=0.67 \mathrm{~V}, J_{\mathrm{sc}}=1.79 \mathrm{~mA} / \mathrm{cm}^{2}$, $\mathrm{FF}=37 \%, \mathrm{PCE}=0.45 \%$. 其中, P3HT 的器件的性能主要
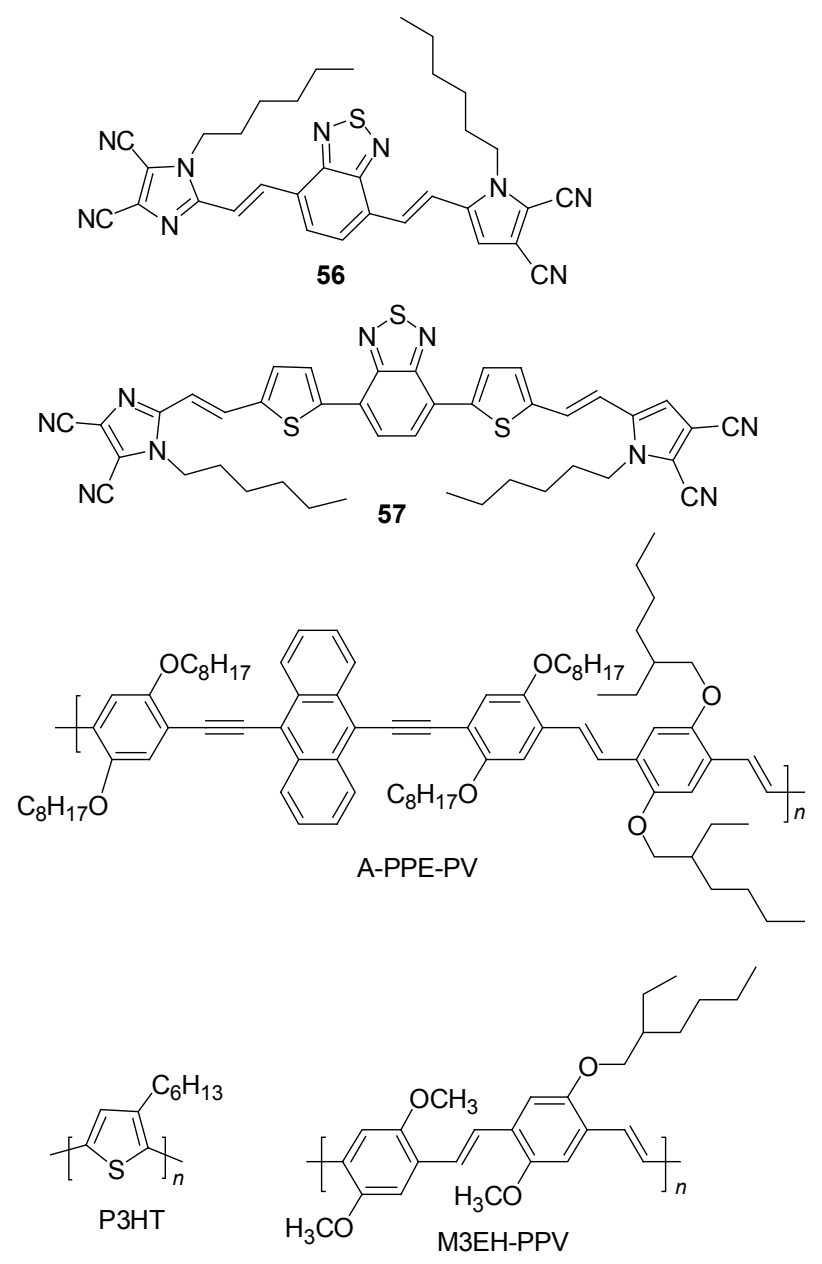

Chart 33 
受限于激子不能有效分离, 而 A-PPE-PPV 为给体时器 件性能则主要因为激子的复合而受限, 从填充系数在 $40 \%$ 以下可以看出, 电荷迁移率较低是这两类器件的主 要问题 ${ }^{[67]}$. 随后, 他们又将 M3EV-PPV 作为电子给体, 经过器件优化, 设计的太阳能电池的填充因子随着给体 受体之间混合程度的降低而提高, 最高达 $57 \%$, 器件的 能量转换效率最高也达到 $0.8 \%{ }^{[68]}$. 在此之后, 又将侧链 氛代的 P3HT 与 56 太阳能电池体系进行了研究, 发现热 处理对器件性能影响很小, 而器件的结构则起着主要作 用, 当以 $\mathrm{P} 3 \mathrm{HT}$ 以及 $\mathrm{P} 3 \mathrm{HT} / \mathbf{5 6}$ 为 $1: 3$ 的混合物制成双层 太阳能电池器件时, 得到了最优化的性能结果: $V_{\mathrm{oc}}=$ $0.85 \mathrm{~V}, J_{\mathrm{sc}}=1.95 \mathrm{~mA} / \mathrm{cm}^{2}, \mathrm{FF}=56 \%, \mathrm{PCE}=0.94 \%{ }^{[69]}$.

Sellinger 等 ${ }^{[70]}$ 进一步研究发现, 将化合物 56 的取 代基增加一个乙基取代基时(即分子 58)可以大大增加材 料的溶解性(Chart 34), 以 $\mathbf{5 8}$ 为受体, 以聚咔唑 $\mathrm{PCz}$ 为给 体材料制备了太阳能电池, 对 $\mathbf{5 8}$ 的含量以及退火温度 进行了篮选, 最终的器件优化结果为 $V_{\mathrm{oc}}=1.36 \mathrm{~V}, J_{\mathrm{sc}}=$ $1.14 \mathrm{~mA} / \mathrm{cm}^{2}, \mathrm{FF}=49 \%, \mathrm{PCE}=0.75 \%$. 此外, 他们对纳 米压印技术在此类器件中的应用进行了研究, 以 P3HT 为给体材料, 以 $\mathbf{5 8}$ 为受体材料, 采用纳米压印技术制备 的双层结构能量转换效率接近本体异质结结构的能量 转换效率 ${ }^{[71]}$. 后续研究发现, 以 3-苯基取代的噻吩聚合 物 POPT 和 P3HT 为给体, 基于 $\mathbf{5 8}$ 为受体材料的两种器 件, 经电极修饰和热处理优化, 效率有了很大提高, 以 POPT 为给体时, 本体异质结器件的性能优化结果为: $V_{\mathrm{oc}}=0.62 \mathrm{~V}, J_{\mathrm{sc}}=5.5 \mathrm{~mA} / \mathrm{cm}^{2}, \mathrm{FF}=40 \%, \mathrm{PCE}=1.4 \%$. 以 $\mathrm{P} 3 \mathrm{HT}$ 为给体时, 本体异质结器件的性能优化结果为: $V_{\mathrm{oc}}=0.76 \mathrm{~V}, J_{\mathrm{sc}}=3.0 \mathrm{~mA} / \mathrm{cm}^{2}, \mathrm{FF}=48 \%, \mathrm{PCE}=1.1 \%$. 得到了迄今为止, 以含有苯并噻二唑的小分子为受体材 料时获得的最高的能量转换效率, 以 POPT 为给体时能 量转换效率较高的原因可能是 POPT 的苯基由于位阻扭 转使得给受体材料间距离更加适合激子的分离所致 ${ }^{[72]}$.

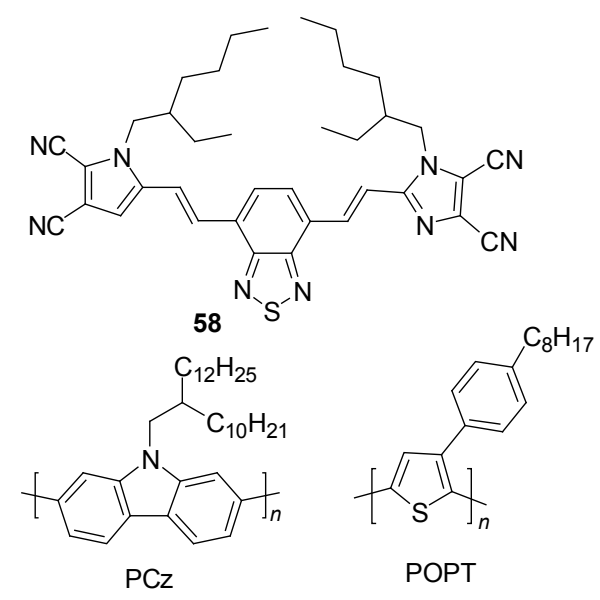

Chart 34

\section{3 苯并噻二唑在染料敏化太阳能电池中的应用}

染料敏化太阳能电池因其对光强度及温度变化不 敏感、光电转换效率高等优点成为近年来太阳能电池领 域的研究热点之一 ${ }^{[73]}$. 尽管钉染料是目前获得的最高 能量转换效率的光敏材料，但由于钉是稀有金属，成本 较高、制备过程复杂而难以大面积推广使用，这使得寻 找全有机的敏化染料成为研究热门 ${ }^{[74]}$, 下面仅就含苯 并噻二唑单元的染料敏化剂近几年的研究进展进行简 单介绍.

2005 年 Velusamy 等 ${ }^{[75]}$ 为了拓宽染料敏化剂的吸收 光谱, 同时提高电荷传输效率并增加敏化剂的稳定性, 首次报道了含有苯并噻二唑的小分子染料敏化剂 59 和 60 (Chart 35), 并对化合物的吸收光谱及光电性能进行 了研究, 测试结果表明, 染料敏化剂 59 制备的太阳能电 池器件性能较高, 具体结果为: $V_{\mathrm{oc}}=0.55 \mathrm{~V}, J_{\mathrm{sc}}=10.44$ $\mathrm{mA} / \mathrm{cm}^{2}, \mathrm{FF}=66 \%, \mathrm{PCE}=3.77 \%$, 而化合物 60 制备的太 阳能电池器件的性能稍低, 具体为: $V_{\mathrm{oc}}=0.52 \mathrm{~V}, J_{\mathrm{sc}}=$ $3.21 \mathrm{~mA} / \mathrm{cm}^{2}, \mathrm{FF}=66 \%, \mathrm{PCE}=1.11 \%$. 作者认为苯基为 桥联基团时，59 是扭曲的非平面构型，减缓了激子的复 合而得到了较高的能量转换效率. 最近, Wong 等 ${ }^{[76]}$ 在 化合物 60 的基础上进一步改进，设计合成了 D-A-A 型 染料敏化剂 61 (Chart 36), 最终制备的太阳能电池器件 能量转换效率达到 $3.16 \%$, 为新型染料敏化剂的设计提 供了方向.
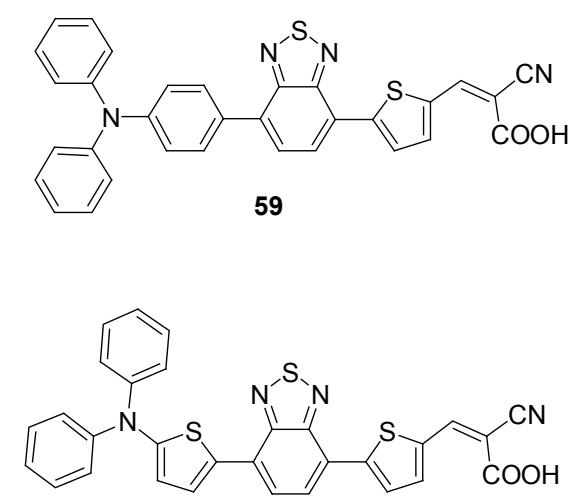

60

Chart 35

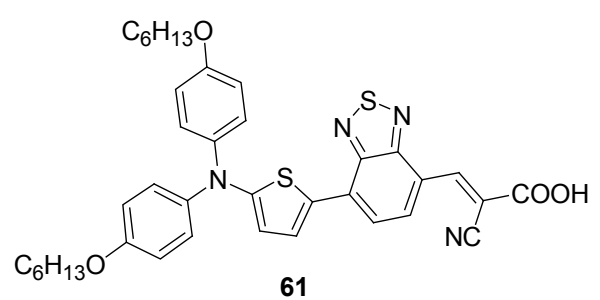

Chart 36 
2008 年, Tian 等 ${ }^{[77]}$ 设计合成了新型染料敏化剂 62 (Chart 37), 吸收光谱范围进一步扩大, 太阳能电池器件 的性能得到了极大提高, 具体结果为 $V_{\mathrm{oc}}=0.54 \mathrm{~V}, J_{\mathrm{sc}}=$ $22.10 \mathrm{~mA} / \mathrm{cm}^{2}, \mathrm{FF}=48 \%, \mathrm{PCE}=7.62 \% .2010$ 年, 他们 ${ }^{[78]}$ 在化合物 62 的基础上, 改变共轭链的结构, 设计合成了 化合物 63 (Chart 37), 以 63 为染料敏化剂的太阳能电池 器件性能结果为: $V_{\mathrm{oc}}=0.50 \mathrm{~V}, J_{\mathrm{sc}}=8.51 \mathrm{~mA} / \mathrm{cm}^{2}, \mathrm{FF}=$ $60 \%, \mathrm{PCE}=2.59 \%$, 由此可以看出, 当炔键改变成单键 时, 共轭效应变差, 尽管供电子单元三苯胺没有变化, 电荷迁移率明显下降, 导致器件能量转换效率降低.

2011 年 Lee 等 ${ }^{[79]}$ 报道了以三苯胺为电子供体, 苯并 噻二唑为受体时, 中间以不同的桥链基团所合成的染料 分子 64 67 (Chart 38), 研究发现, 单键桥键因具有较
好的电荷分离能而表现高的能量转换效率，随着大位阻 供电子烷氧基链的引入, 分子共轭体系进一步加强, 同 时阻断了分子在二氧化钠膜中的聚集, 能量转换效率显 著提高, 以 67 为染料分子时制备的太阳能电池光敏器 件的最终结果为: $V_{\mathrm{oc}}=0.62 \mathrm{~V}, J_{\mathrm{sc}}=17.9 \mathrm{~mA} / \mathrm{cm}^{2}, \mathrm{FF}=$ $66 \%, \mathrm{PCE}=7.30 \%$.

吲哚类染料是基于纯有机光敏染料太阳能电池的 常用光敏剂之一 ${ }^{[80]}, 2011$ 年, Tian 等 ${ }^{[81]}$ 以吲哚衍生物为 电子给体单元, 苯并噻二唑为桥联共轭基团, 以氧基乙 酸基为电子受体单元, 进一步拓宽吸收光谱的范围并增 加材料的稳定性，设计合成了化合物 68 (Chart 39), 制 备的太阳能电池光敏器件的最优化性能结果为: $V_{\mathrm{oc}}=$

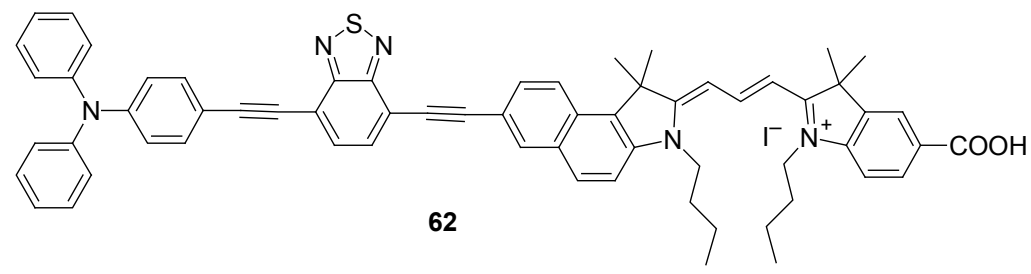<smiles>CCCCN1C(/C=C/C=C/C2=[N+](CCCC)c3ccc(C(=O)O)cc3C2(C)C)=C(C)C(C)(C)c2c1ccc1cc(C#Cc3ccc(-c4ccc(N(c5ccccc5)c5ccccc5)cc4)c4nsnc34)ccc21</smiles>

Chart 37<smiles></smiles>

64<smiles></smiles>

66<smiles></smiles>

65

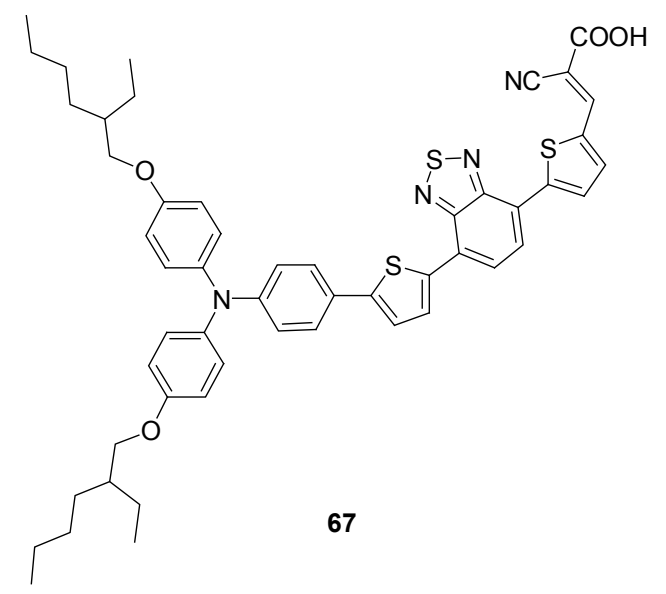

Chart 38 
$0.65 \mathrm{~V}, J_{\mathrm{sc}}=17.7 \mathrm{~mA} / \mathrm{cm}^{2}, \mathrm{FF}=76 \%, \mathrm{PCE}=8.7 \%$, 很好 的调节了吲哚啉单元的电子分布, 而且染料敏化剂的稳 定性有了很大提高.

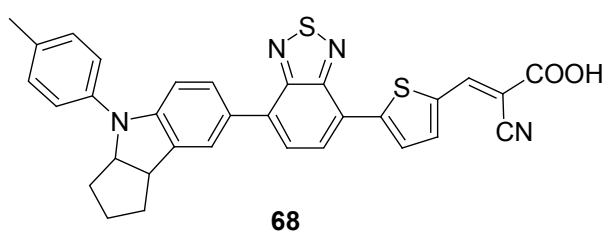

Chart 39

为了提高光敏剂 68 的开路电压, Tian 等 ${ }^{[82]}$ 在分析上 述研究的基础上认为, 由于噻吩单元作为 $\pi$ 共轭桥使得 分子具有较好的共平面效应, 然而分子容易形成 $\pi$ 堆积, 进而导致分子聚集, 出现电荷淬灭和激子复合. 于是, 作者在上述结构的基础上, 将正已基引入共轭桥塞吩单 元上制备了敏化染料分子 69 (Chart 40), 成功地改变了 染料的聚集状态. 进一步的研究表明, 染料分子 68 的高 转换效率主依赖于染料敏化时所使用的溶剂和添加剂, 而分子 69 则对使用的溶剂和添加剂不敏感, 表现出了 一定的抗聚集能力, 瞬态光电压和光电流衰减实验以及 电化学阻抗分析表明电子注入寿命和电荷复合阻力由 于正己基的引入明显得到提到, 优化后的能量转化效率 高达 9.04\%, 开路电压和短路电流分别为 $0.696 \mathrm{~V}$ 和 $18.00 \mathrm{~mA} / \mathrm{cm}^{2}$. 然而在苯并塞二唑与吲哚啉间再加入一 个烷基取代的噻吩单元合成的染料分子 70 (Chart 40), 虽然进一步增大了共轭链, 扩展光电流的响应范围, 却 没有提高染料分子的能量转化效率 ${ }^{[83]}$. 该研究为染料 敏化太阳能电池材料的设计提供了新思路, 也从敏化染 料分子的聚集状态、能量转化机理方面对新型染料分子 的结构调控提供了更加详尽的理论支持.

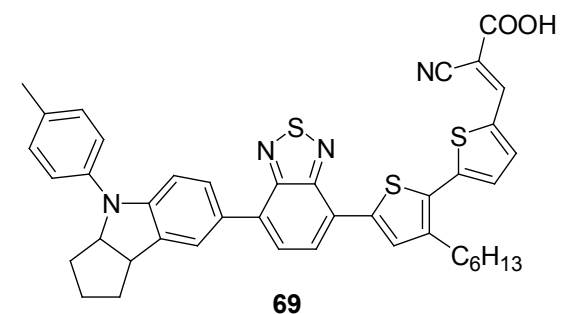

69

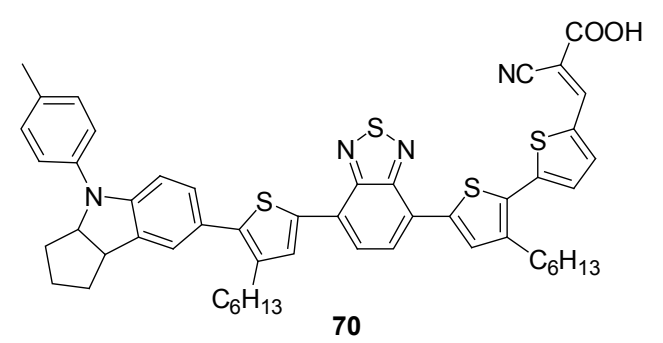

Chart 40

\section{4 结语}

本文对近年来苯并噻二唑在有机太阳能电池中的 应用进行了综述. 从中可以看出, 苯并噻二唑作为良好 的电子受体单元在聚合物太阳能电池材料以及小分子 太阳能电池材料中都得到了广泛的应用，部分材料表现 出较高的能量转换效率, 是当今有机太阳能电池器件中 的重要组成部分. 通过对材料能级的合理调控、活性层 形貌优化以及退火温度和退火时间的调节，太阳能电池 器件的能量转换效率必将进一步提高, 相信有机太阳能 电池的商业化应用在不久的将来就可以得到实现.

\section{References}

[1] (a) Ning, Z. J.; Tian, H. Chem. Commun. 2009, 5483.

(b) Pivrikas, A.; Neugebauer, H.; Sariciftci, N. S. Sol. Energy 2011, $85,1226$.

(c) Zhang, T. H.; Piao, L. Y.; Zhao, S. L.; Xu, Z.; Yang, L.; Liu, X. Z.; Ju, S. T. Chin. J. Org. Chem. 2011, 31, 260 (in Chinese). (张天慧, 朴玲钰, 赵囬玲, 徐征, 杨否, 刘祥志, 鞠思婷, 有机 化学, 2011, 31, 260.)

(d) Li, Y. F. Acc. Chem. Res. 2012, 45, 723.

[2] (a) Gunes, S.; Neugebauer, H.; Sariciftci, N. S. Chem. Rev. 2007, 107,1324

(b) Bundgaard, E.; Krebs, F. C. Sol. Energy Mater. Sol. Cells 2007, 91, 954.

(c) Chen, J. W.; Cao, Y. Acc. Chem. Res. 2009, 42, 1709.

(d) Zhang, Z. G.; Wang, J. Z. J. Mater. Chem. 2012, 22, 4178.

(e) Ye, H. Y.; Li, W.; Li, W. S. Chin. J. Org. Chem. 2012, 32, 266 (in Chinese)

(叶怀英, 李文, 李维实, 有机化学, 2012, 32, 266.)

[3] (a) Dhanabalan, A.; van Duren, J. K. J.; van Hal, P. A.; van Dongen, J. L. J.; Janssen, R. A. J. Adv. Funct. Mater. 2001, 11, 255. (b) van Duren, J. K. J.; Dhanabalan, A.; van Hal, P. A.; Janssen, R. A. J. Synth. Met. 2001, 121, 1587.

(c) Dhanabalan, A.; van Hal, P. A.; van Duren, J. K. J.; van Dongen, J. L. J.; Janssen, R. A. J. Synth. Met. 2001, 119, 169.

[4] (a) Winder, C.; Sariciftci, N. S. J. Mater. Chem. 2004, 14, 1077. (b) Hoppe, H.; Sariciftci, N. S. J. Mater. Res. 2004, 19, 1924.

[5] Bundgaard, E.; Krebs, F. C. Polym. Bull. 2005, 55, 157.

[6] Wienk, M. M.; Struijk, M. P.; Janssen, R. A. J. Chem. Phys. Lett. 2006, 422, 488.

[7] Bundgaard, E.; Krebs, F. C. Macromolecules 2006, 39, 2823.

[8] Bundgaard, E.; Krebs, F. C. Sol. Energy Mater. Sol. Cells 2007, 91, 1019.

[9] Bundgaard, E.; Shaheen, S. E.; Krebs, F. C.; Ginley, D. S. Sol. Energy Mater. Sol. Cells 2007, 91, 1631.

[10] Lim, B.; Jo, J.; Khim, D.; Jeong, H. G.; Yu, B. K.; Kim, J.; Kim, D. Y. Org. Electron. 2010, 11, 1772.

[11] Zhao, G. J.; He, Y. J.; He, C.; Fan, H. J.; Zhao, Y.; Li, Y. F. Sol. Energy Mater. Sol. Cells 2011, 95, 704.

[12] Zhang, F. L.; Jespersen, K. G.; Björström, C.; Svensson, M.; Andersson, M. R.; Sundström, V.; Magnusson, K.; Moons, E.; Yartsev, A.; Inganäs, O. Adv. Funct. Mater. 2006, 16, 667.

[13] Slooff, L. H.; Veenstra, S. C.; Kroon, J. M.; Moet, D. J. D.; Sweelssen, J.; Koetse, M. M. Appl. Phys. Lett. 2007, 90, 143506.

[14] Shi, C. J.; Yao, Y.; Yang, Y.; Pei, Q. B. J. Am. Chem. Soc. 
2006, 128,8980 .

[15] Yao, Y.; Shi, C. J.; Li, G.; Shrotriya, V.; Pei, Q. B.; Yang, Y. Appl. Phys. Lett. 2006, 89, 153507.

[16] Wang, E. G.; Wang, M.; Wang, L.; Duan, C. H.; Zhang, J.; Cai, W. Z.; He, C.; Wu, H. B.; Cao, Y. Macromolecules 2009, 42, 4410 .

[17] Boudreault, P. L. T.; Michaud, A.; Leclerc, M. Macromol. Rapid Commun. 2007, 28, 2176.

[18] Wang, E.; Wang, L.; Lan, L.; Luo, C.; Zhuang, W.; Peng, J.; Cao, Y. Appl. Phys. Lett. 2008, 92, 033307.

[19] Liu, M.; Wang, Y.; Zhang, Z. Y.; Li, J. M.; Liu, Y.; Tan, H.; Ni, M. J.; Lei, G. T.; Zhu, M. X.; Zhu, W. G. J. Polym. Sci. Part A: Polym. Chem. 2011, 49, 3874.

[20] Piyakulawat, P.; Keawprajak, A.; Jiramitmongkon, K.; Hanusch, M.; Wlosnewski, J.; Asawapirom, U. Sol. Energy Mater. Sol. Cells 2011, 95, 2167.

[21] Blouin, N.; Michaud, A.; Leclerc, M. Adv. Mater. 2007, 19, 2295.

[22] Blouin, N.; Michaud, A.; Gendron, D.; Wakim, S.; Blair, E.; Neagu-Plesu, R.; Belletête, M.; Durocher, G.; Tao, Y.; Leclerc, M. J. Am. Chem. Soc. 2008, 130, 732.

[23] Park, S. H.; Roy, A.; Beaupre, S.; Cho, S.; Coates, N.; Moon, J. S.; Moses, D.; Leclerc, M.; Lee, K. H.; Heeger, A. J. Nat. Photonics 2009, 3, 297.

[24] Cho, S.; Seo, J. H.; Park, S. H.; Beaupré, S.; Leclerc, M.; Heeger, A. J. Adv. Mater. 2010, 22, 1253.

[25] Peters, C. H.; Sachs-Quintana, I. T.; Kastrop, J. P.; Beaupré, S.; Leclerc, M.; McGehee, M. D. Adv. Energy Mater. 2011, 1, 491.

[26] Qin, R. P.; Li, W. W.; Li, C. H.; Du, C.; Veit, C.; Schleiermacher, H. F.; Andersson, M.; Bo, Z. S.; Liu, Z. P.; Inganas, O.; Wuerfel, U.; Zhang, F. L. J. Am. Chem. Soc. 2009, 131, 14612.

[27] Liu, X.; Wen, W.; Bazan, G. C. Adv. Mater. 2012, 24, 4505.

[28] Kim, J.; Yun, M. H.; Anant, P.; Cho, S.; Jacob, J.; Kim, J. Y.; Yang, C. Chem. Eur. J. 2011, 17, 14681.

[29] Tsai, J. H.; Chueh, C. C.; Lai, M. H.; Wang, C. F.; Chen, W. C.; Ko, B. T.; Ting, C. Macromolecules 2009, 42, 1897.

[30] Zhou, E.; Yamakawa, S.; Zhang, Y.; Tajima, K.; Yang, C.; Hashimoto, K. J. Mater. Chem. 2009, 19, 7730.

[31] Xia, Y. J.; Su, X. H.; He, Z. C.; Ren, X.; Wu, H. B.; Cao, Y.; Fan, D. W. Macromol. Rapid Commun. 2010, 31, 1287.

[32] Lu, J. P.; Liang, F. S.; Drolet, N.; Ding, J. F.; Tao, Y.; Movileanu, R. Chem. Commun. 2008, 5315.

[33] Cheng, Y. J.; Wu, J. S.; Shih, P. I.; Chang, C. Y.; Jwo, P. C.; Kao, W. S.; Hsu, C. S. Chem. Mater. 2011, 23, 2361.

[34] Mühlbacher, D.; Scharber, M.; Morana, M.; Zhu, Z.; Waller, D.; Gaudiana, R.; Brabec, C. Adv. Mater. 2006, 18, 2884.

[35] Soci, C.; Hwang, I. W.; Moses, D.; Zhu, Z.; Waller, D.; Gaudiana, R.; Brabec, C. J.; Heeger, A. J. Adv. Funct. Mater. 2007, 17, 632.

[36] Zhu, Z.; Waller, D.; Gaudiana, R.; Morana, M.; Mühlbacher, D.; Scharber, M.; Brabec, C. Macromolecules 2007, 40, 1981.

[37] Moulé, A. J.; Tsami, A.; Bünnagel, T. W.; Forster, M.; Kronenberg, N. M.; Scharber, M.; Koppe, M.; Morana, M.; Brabec, C. J.; Meerholz, K.; Scherf, U. Chem. Mater. 2008, 20, 4045.

[38] Peet, J.; Kim, J. Y.; Coates, N. E.; Ma, W. L.; Moses, D.; Heeger, A. J.; Bazan, G. C. Nat. Mater. 2007, 6, 497.

[39] Lee, J. K.; Ma, W. L.; Brabec, C. J.; Yuen, J.; Moon, J. S.; Kim, J. Y.; Lee, K.; Bazan, G. C.; Heeger, A. J. J. Am. Chem. Soc. 2008, $130,3619$.

[40] Kim, J. Y.; Lee, K.; Coates, N. E.; Moses, D.; Nguyen, T. Q.; Dante, M.; Heeger, A. J. Science 2007, 317, 222.

[41] Lee, U. R.; Lee, T. W.; Hoang, M. H.; Kang, N. S.; Yu, J. W.; Kim, K. H.; Lim, K. G.; Lee, T. W.; Jin, J. I.; Choi, D. H. Org. Electron.
2011, 12, 269

[42] Lee, S. K.; Seo, J. H.; Cho, N. S.; Cho, S. Thin Solid Films 2012, $520,5438$.

[43] Zhou, E.; Nakamura, M.; Nishizawa, T.; Zhang, Y.; Wei, Q.; Tajima, K.; Yang, C.; Hashimoto, K. Macromolecules 2008, 41, 8302.

[44] Yue, W.; Zhao, Y.; Shao, S. Y.; Tian, H. K.; Xie, Z. Y.; Geng, Y. H.; Wang, F. S. J. Mater. Chem. 2009, 19, 2199.

[45] Hou, J. H.; Chen, H. Y.; Zhang, S. Q.; Li, G.; Yang, Y. J. Am. Chem. Soc. 2008, 130, 16144.

[46] Coffin, R. C.; Peet, J.; Rogers, J.; Bazan, G. C. Nat. Chem. 2009, 1, 657.

[47] Beaujuge, P. M.; Tsao, H. N.; Hansen, M. R.; Amb, C. M.; Risko, C.; Subbiah, J.; Choudhury, K. R.; Mavrinskiy, A.; Pisula, W.; Brédas, J. L.; So, F.; Mullen, K.; Reynolds, J. R. J. Am. Chem. Soc. 2012, 134, 8944.

[48] Fei, Z.; Kim, J. S.; Smith, J.; Domingo, E. B.; Anthopoulos, T. D.; Stingelin, N.; Watkins, S. E.; Kim, J. S.; Heeney, M. J. Mater. Chem. 2011, 21, 16257.

[49] (a) Pan, H. L.; Li, Y. N; Wu, Y. L.; Liu, P.; Ong, B. S.; Zhu, S. P.; Xu, G. J. Am. Chem. Soc. 2007, 129, 4112.

(b) Hou, J. H.; Chen, H. Y.; Zhang, S. Q.; Chen, R. I.; Yang, Y.; Wu, Y.; Li, G. J. Am. Chem. Soc. 2009, 131, 15586.

(c) Liang, Y. Y.; Xu, Z.; Xia, J. B.; Tsai, S. T.; Wu, Y.; Li, G.; Ray, C.; Yu, L. P. Adv. Mater. 2010, 22, E135.

(d) Liang, Y. Y.; Feng, D. Q.; Wu, Y.; Tsai, S. T.; Li, G.; Ray, C.; Yu, L. P. J. Am. Chem. Soc. 2009, 131, 7792.

[50] Hou, J. H.; Chen, H. Y.; Zhang, S. Q.; Yang, Y. J. Phys. Chem. C 2009, 113, 21202.

[51] Huo, L. J.; Hou, J. H.; Zhang, S. Q.; Chen, H. Y.; Yang, Y. Angew. Chem., Int. Ed. 2010, 49, 1500.

[52] Peng, Q.; Liu, X. J.; Su, D.; Fu, G. W.; Xu, J.; Dai, L. M. $A d v . M a-$ ter. 2011, 23, 4554.

[53] (a) Zhang, Y.; Zou, J. Y.; Cheuh, C. C.; Yip, H. L.; Jen, A. K. Y. Macromolecules 2012, 45, 5427.

(b) Zhou, H. X.; Yang, L. Q.; Stuart, A. C.; Price, S. C.; Liu, S. B.; You, W. Angew. Chem., Int. Ed. 2011, 50, 2995.

[54] Wang, M.; Hu, X. W.; Liu, P.; Li, W.; Gong, X.; Huang, F.; Cao, Y. J. Am. Chem. Soc. 2011, 133, 9638.

[55] Chan, S. H.; Chen, C. P.; Chao, T. C.; Ting, C.; Lin, C. S.; Ko, B. T. Macromolecules 2008, 41, 5519.

[56] Chen, C. P.; Chan, S. H.; Chao, T. C.; Ting, C.; Ko, B. T. J. Am. Chem. Soc. 2008, 130, 12828.

[57] Zhang, M. J.; Guo, X.; Wang, X. C.; Wang, H. Q.; Li, Y. F. Chem. Mater. 2011, 23, 4264.

[58] Wong, W. Y.; Wang, X. Z.; He, Z.; Djurisic, A. B.; Yip, C. T.; Cheung, K. Y.; Wang, H.; Mak, C. S. K.; Chan, W. K. Nat. Mater. 2007, 6, 521 .

[59] Baek, N. S.; Hau, S. K.; Yip, H. L.; Acton, O.; Chen, K. S.; Jen, A. K. Y. Chem. Mater. 2008, $20,5734$.

[60] He, C.; He, Q. G.; He, Y. J.; Li, Y. F.; Bai, F. L.; Yang, C. H.; Ding, Y. Q.; Wang, L. X.; Ye, J. P. Sol. Energy Mater. Sol. Cells 2006, 90, 1815.

[61] He, C.; He, Q. G.; Yi, Y. P.; Wu, G. L.; Bai, F. L.; Shuai, Z. G.; Li, Y. F. J. Mater. Chem. 2008, 18, 4085.

[62] Wu, G. L.; Zhao, G. J.; He, C.; Zhang, J.; He, Q. G.; Chen, X. M.; Li, Y. F. Sol. Energy Mater. Sol. Cells 2009, 93, 108.

[63] Li, W. W.; Du, C.; Li, F. H.; Zhou, Y.; Fahlman, M.; Bo, Z. S.; Zhang, F. L. Chem. Mater. 2009, 21, 5327.

[64] Zhang, J.; Yang, Y.; He, C.; He, Y.; Zhao, G. J.; Li, Y. F. Macromolecules 2009, 42, 7619.

[65] Shang, H. X.; Fan, H. J.; Liu, Y.; Hu, W. P.; Li, Y. F.; Zhan, X. W. Adv. Mater. 2011, 23, 1554. 
[66] Shin, R. Y. C.; Kietzke, T.; Sudhakar, S.; Dodabalapur, A.; Chen, Z. K.; Sellinger, A. Chem. Mater. 2007, 19, 1892.

[67] Kietzke, T.; Shin, R. Y. C.; Egbe, D. A. M.; Chen, Z. K.; Sellinger, A. Macromolecules 2007, 40, 4424.

[68] Schubert, M.; Yin, C.; Castellani, M.; Bange, S.; Tam, T. L.; Sellinger, A.; Horhold, H. H.; Kietzke, T.; Neher, D. J. Chem. Phys. 2009, 130, 094703.

[69] Inal, S.; Castellani, M.; Sellinger, A.; Neher, D. Macromol. Rapid Commun. 2009, 30, 1263.

[70] Ooi, Z. E.; Tam, T. L.; Shin, R. Y. C.; Chen, Z. K.; Kietzke, T.; Sellinger, A.; Baumgarten, M.; Mullen, K.; de Mello, J. C. J. Mater. Chem. 2008, 18, 4619.

[71] Zeng, W. J.; Chong, K. S. L.; Low, H. Y.; Williams, E. L.; Tam, T. L.; Sellinger, A. Thin Solid Films 2009, 517, 6833.

[72] Woo, C. H.; Holcombe, T. W.; Unruh, D. A.; Sellinger, A.; Fréchet, J. M. J. Chem. Mater. 2010, 22, 1673.

[73] (a) Hagfeldt, A.; Boschloo, G.; Sun, L.; Kloo, L.; Pettersson, H. Chem. Rev. 2010, 110, 6595.

(b) Imahori, H.; Umeyama, T.; Ito, S. Acc. Chem. Res. 2009, 42, 1809.

(c) Clifford, J. N.; Martinez-Ferrero, E.; Viterisi, A.; Palomares, E. Chem. Soc. Rev. 2011, 40, 1635.

(d) Snaith, H. J. Adv. Funct. Mater. 2010, 20, 13.

(e) Ning, Z. J.; Fu, Y.; Tian, H. Energy Environ. Sci. 2010, 3, 1170.

[74] (a) Wang, Z. S.; Cui, Y.; Hara, K.; Dan-oh, Y.; Kasada, C.; Shinpo, A. Adv. Mater. 2007, 19, 1138.

(b) Mishra, A.; Fischer, M. K. R.; Bäuerle, P. Angew. Chem., Int. Ed. 2009, 48, 2474

(c) Hara, K.; Wang, Z. S.; Cui, Y.; Furube, A.; Koumura, N. Energy Environ. Sci. 2009, 2, 1109

(d) Ooyama, Y.; Harima, Y. Eur. J. Org. Chem. 2009, 2903. (e) Chen, C. H.; Hsu, Y. C.; Chou, H. H.; Thomas, K. R. J.; Lin, J. T.; Hsu, C. P. Chem. Eur. J. 2010, 16, 3184.

(f) Li, W. Q.; Wu, Y. Z.; Li, X.; Xie, Y. S.; Zhu, W. H. Energy Environ. Sci. 2011, 4, 1830.

(g) Qu, S. Y.; Hua, J. L.; Tian, H. Sci. China Chem. 2012, 55, 677.

(h) Kim, B. G.; Zhen, C. G.; Jeong, E. J.; Kieffer, J.; Kim, J. $A d v$. Funct. Mater. 2012, 22, 1606.

[75] Velusamy, M.; Justin Thomas, K. R.; Lin, J. T.; Hsu, Y. C.; Ho, K. C. Org. Lett. 2005, 7, 1899.

[76] Lin, L. Y.; Tsai, C. H.; Lin, F.; Huang, T. W.; Chou, S. H.; Wu, C. C.; Wong, K. T. Tetrahedron 2012, 68, 7509.

[77] Ma, X. M.; Hua, J. L.; Wu, W. J.; Jin, Y. H.; Meng, F. S.; Zhan, W. H.; Tian, H. Tetrahedron 2008, 64, 345.

[78] Li, J. Wu, W. J.; He, J. X.; Hua, J. L. Acta Chim. Sinica 2010, 24, 2551 (in Chinese).

(李晶, 武文俊, 贺锦香, 花建丽, 化学学报, 2010, 24, 2551.)

[79] Lee, D. H.; Lee, M. J.; Song, H. M.; Song, B. J.; Seo, K. D.; Pastore, M.; Anselmi, C.; Fantacci, S.; De Angelis, F.; Nazeeruddin, M. K.; Gräetzel, M.; Kim, H. K. Dyes Pigm. 2011, 91, 192.

[80] (a) Liu, B.; Zhu, W. H.; Zhang, Q.; Wu, W. J.; Xu, M.; Ning, Z. J.; Xie, Y. S.; Tian, H. Chem. Commun. 2009, 1766.

(b) Ito, S.; Miura, H.; Uchida, S.; Takata, M.; Sumioka, K.; Liska, P.; Comte, P.; Pechy, P.; Gratzel, M. Chem. Commun. 2008, 5194.

(c) Snaith, H. J.; Petrozza, A.; Ito, S.; Miura, H.; Gratzel, M. Adv. Funct. Mater. 2009, 19, 1810.

[81] Zhu, W. H.; Wu, Y. Z.; Wang, S. T.; Li, W. Q.; Li, X.; Chen, J.; Wang, Z. S.; Tian, H. Adv. Funct. Mater. 2011, 21, 756.

[82] Wu, Y. Z.; Marszalek, M.; Zakeeruddin, S. M.; Zhang, Q.; Tian, H.; Gratzel, M.; Zhu, W. H. Energy Environ. Sci. 2012, 5, 8261.

[83] Wu, Y. Z.; Zhang, X.; Li, W. Q.; Wang, Z. S.; Tian, H.; Zhu, W. H. Adv. Energy Mater. 2012, 2, 149..

(Qin, X.) 